\title{
A multiphysical ensemble system of numerical snow modelling
}

\author{
Matthieu Lafaysse, Bertrand Cluzet, Marie Dumont, Yves Lejeune, Vincent Vionnet, and Samuel Morin \\ Météo-France - CNRS, CNRM UMR3589, Centre d'Études de la Neige (CEN), Grenoble, France \\ Correspondence to: Matthieu Lafaysse (matthieu.lafaysse@meteo.fr)
}

Received: 17 December 2016 - Discussion started: 10 January 2017

Revised: 28 March 2017 - Accepted: 3 April 2017 - Published: 11 May 2017

\begin{abstract}
Physically based multilayer snowpack models suffer from various modelling errors. To represent these errors, we built the new multiphysical ensemble system ESCROC (Ensemble System Crocus) by implementing new representations of different physical processes in the deterministic coupled multilayer ground/snowpack model SURFEX/ISBA/Crocus. This ensemble was driven and evaluated at $\mathrm{Col}$ de Porte (1325 ma.s.l., French alps) over 18 years with a high-quality meteorological and snow data set. A total number of 7776 simulations were evaluated separately, accounting for the uncertainties of evaluation data. The ability of the ensemble to capture the uncertainty associated to modelling errors is assessed for snow depth, snow water equivalent, bulk density, albedo and surface temperature. Different sub-ensembles of the ESCROC system were studied with probabilistic tools to compare their performance. Results show that optimal members of the ESCROC system are able to explain more than half of the total simulation errors. Integrating members with biases exceeding the range corresponding to observational uncertainty is necessary to obtain an optimal dispersion, but this issue can also be a consequence of the fact that meteorological forcing uncertainties were not accounted for. The ESCROC system promises the integration of numerical snow-modelling errors in ensemble forecasting and ensemble assimilation systems in support of avalanche hazard forecasting and other snowpack-modelling applications.
\end{abstract}

\section{Introduction}

Operational forecasting of avalanche hazard requires an analysis of current snowpack state and meteorological forecasts for the upcoming days, in order to estimate future snow conditions. Several organisations in different countries have implemented snowpack-modelling approaches for this pur- pose (Durand et al., 1999; Lehning et al., 1999; VikhamarSchuler et al., 2011; Bellaire and Jamieson, 2013). The goal is to provide a description of the space and time variability of the current snowpack, which is out of reach using observations only and to anticipate its evolution according to the expected meteorological conditions a few hours to days ahead. Meteo-France has been operating a deterministic snowpack forecasting system for about 20 years. The current version is based on a chain of three models: SAFRANSURFEX/ISBA/Crocus-MEPRA (S2M, Durand et al., 1999; Lafaysse et al., 2013). It simulates the snowpack evolution over all the French massifs for a large range of elevations, slope values and aspects. The meteorological analysis and forecasting system, SAFRAN (Durand et al., 1993), provides meteorological data at a $1000 \mathrm{~km}^{2}$ scale for a given elevation from the beginning of the season with a 2-day forecast lead time. These data are used to force the SURFEX/ISBA/Crocus snowpack model (Vionnet et al., 2012) which simulates the detailed snowpack stratigraphy for the different elevations and slopes. The mechanical stability of each snow profile is assessed by the MEPRA expert system (Giraud, 1992). This system is supposed to help the forecasters in their decision process. However, the large discrepancies between this simulation system and the observed or perceived conditions in the field limit its practical interest relative to empirical considerations based on snow stratigraphy, surface properties measurements and the outputs of numerical weather prediction (NWP) models. Similar issues are found by the other organisations operating systems based either on SURFEX/ISBA/Crocus or on the SNOWPACK snow model of similar complexity (Bartelt and Lehning, 2002).

Snowpack-modelling systems suffer from various types of uncertainties. First, the estimated meteorological conditions since the beginning of the season are uncertain because meteorological analysis systems such as SAFRAN only assimilate scattered meteorological observations and suffer from the er- 
rors of their guess, usually analyses or forecasts of NWP models. NWP models errors, due to both initial states approximations and simplifications in atmospheric modelling, are also responsible for significant errors of the meteorological forcing for the forecast period. In addition, uncertainties are associated with the spatial resolution of the systems which are much coarser than the spatial scale of the snowpack variability involved in avalanche release mechanisms. Finally, snowpack modelling inherently contains simplifications and parameters uncertainties.

It is necessary to better quantify the uncertainties resulting from these different errors for two main reasons. First, an objective quantification of uncertainties helps forecasters assess the confidence they may have in a specific model forecast on a specific date. Second, a better knowledge of uncertainties is necessary to reduce model error by using data assimilation techniques to correct the simulated snowpack state with ground-based or remotely sensed snow observations. In other disciplines, such as meteorology and hydrology, ensemble approaches are now generalized (Swinbank et al., 2016), especially for the furthest prediction lead times when the uncertainty is increasing. Ensemble simulations also increase confidence in future climate simulations (IPCC, 2013). Several data assimilation techniques are also based on building ensembles to characterise guess errors. Therefore, ensemble approaches are a natural candidate for quantifying uncertainties in numerical snow modelling. Vernay et al. (2015) illustrated that the uncertainty of the meteorological forecast can be taken into account by forcing a snowpack model using ensemble NWP systems, and that it improves the robustness of the snowpack simulations compared to the deterministic approach. Charrois et al. (2016) implemented an ensemble assimilation algorithm that is able to correct snowpack simulations using remotely sensed visible spectral reflectances of the surface if the ensemble captures all the possible states of the snowpack. To generalize these methods, all the uncertainties involved in numerical snow modelling must be accounted for in ensemble systems. Accounting for all the main uncertainties (meteorological forecast, initial conditions, model structure) has been shown to improve the overall skill of ensemble simulations for hydrology (Thiboult et al., 2016).

Concerning the uncertainty attached to the snowpack model, Essery et al. (2013) proposed the first attempt to build an ensemble of snow simulations based on 1701 different combinations of physical options for various processes in a common model structure called JIM (JULES Investigation Model). A reduced version of 32 members (FSM, Factorial Snowpack Model) was also published by Essery (2015). This system was designed to investigate the relative contribution of each main physical process in the spread usually obtained in model intercomparison projects. Therefore, the JIM ensemble spread describes the uncertainty resulting from currently available multilayer snow models of different complexities. The authors identified minimal requirements for a satisfactory snowpack model (e.g. prognostic representation of snow albedo and density), but they also conclude that there is not a single best member for all criteria and seasons. Their results also demonstrate that evaluations restricted to snow depth measurements only and/or to a small number of seasons can lead to misleading conclusions. Raleigh et al. (2015) compared the spread of the JIM ensemble with ensemble simulations resulting from disturbed meteorological scenarios and found that the uncertainty in meteorological data prevails in general applications of numerical snow modelling except in very well-instrumented observatories where snow model structure becomes the main source of uncertainty. The JIM ensemble spread was not characterised from a probabilistic point of view (adequate dispersion for ensemble applications, i.e. representative of model errors) because it was not designed for that. Note also that the JIM ensemble is not appropriate for avalanche hazard forecasting because it does not include a detailed description of snow stratigraphy and snow metamorphism, and because some of the members include options which neglect processes known to be critical for mechanical stability such as compaction or liquid water storage.

The goal of this paper is to investigate the uncertainty involved in the different processes of a detailed multilayer snowpack model (SURFEX/ISBA/Crocus) in order to explore the possibility of building an ensemble version of this model suited for snowpack ensemble forecast and snowpack ensemble assimilation applications. Our aim differs from that of Essery et al. (2013) because we expect this ensemble to consist of members with the same overall degree of complexity and type of output, and to include a detailed stratigraphy of the snowpack allowing applications such as avalanche hazard forecasting, among others. Ideally the skill of one given member should not be significantly poorer than another one in a general perspective (for various variables, sites, seasons and periods of the year). The spread of this ensemble should be of the same magnitude as that of typical model errors (Fortin et al., 2014) on different evaluation variables. This should allow for correct characterisation of the uncertainty in real-time applications. Such a system would also allow the snowpack model error to be accounted for in snow hydrology and in future snowpack projections driven by future climate scenarios.

The major difficulty in building such an ensemble is that it requires isolating the uncertainty originating from the snowpack model itself from the other uncertainty sources. Therefore, following the conclusions of Raleigh et al. (2015) and similarly to Essery et al. (2013), our strategy is to build and evaluate our ensemble on one specific well-instrumented site where we assume that input meteorological errors are low compared to model errors. It also allows us to follow Essery et al. (2013) recommendations in terms of evaluation data because numerous snow variables are available over a long period. Section 2 summarises the data set used to force and evaluate a new multiphysical version of the Crocus snow- 
pack model called ESCROC (Ensemble System Crocus) and presented in Sect. 3. The evaluation methodology (Sect. 4) includes both a classical deterministic evaluation member by member and a probabilistic evaluation of the ensemble skill. The results are presented in Sect. 5 for different subensembles. The limitations of the "perfect meteorological forcing" assumption are discussed in Sect. 6, as well as the impacts of the other limitations of our methodology on the possible applications of ensemble numerical modelling of snow.

\section{Data set}

\subsection{Forcing data}

The 18-year long snow and meteorological data set from the Col de Porte observatory (CDP, $1325 \mathrm{~m}$ altitude, $45.3^{\circ} \mathrm{N}$, $5.77^{\circ} \mathrm{S}$ ) is used to force and evaluate ESCROC from 1993 to 2011. A complete description of the data set is provided by Morin et al. (2012). The CDP site is a grassy meadow characterised by its mid-altitude and located in the Chartreuse massif in the French Alps. Snow is usually present from December to April, but snowmelt and rainfall events can occur any time in the snow season. Wind is usually low, so drifting events are unusual. The quality and completeness of this data set have made it possible to drive and evaluate various snowpack models (e.g. Magnusson et al., 2015; Decharme et al., 2016, a complete list is available at http://www.umr-cnrm.fr/spip.php?article533). All the forcing variables of the Crocus model are directly measured: incident shortwave and longwave radiations, $2 \mathrm{~m}$ air temperature and specific humidity as well as $10 \mathrm{~m}$ wind speed and precipitation rates. Precipitation phase is manually assessed using all possible ancillary information. The only modification applied to the original published data set is a bias correction of the incident longwave correction. Indeed, a break was identified in the time series in December 2010, associated with a replacement of the sensor. A $-10 \mathrm{Wm}^{-2}$ homogeneous correction is applied before December 2010 and a $+10 \mathrm{Wm}^{-2}$ homogeneous correction is applied from December 2010 onwards. These values were estimated from the concomitant evolution of the monthly mean difference between these data and the longwave incident radiation simulated by the Ritter and Geleyn (1992) radiative transfer scheme included in SAFRAN meteorological reanalyses (Durand et al., 2009). Although this correction is lower than the manufacturer uncertainty of $10 \%$ (Morin et al., 2012), it has a significant impact on snow simulations (not shown), consistent with the results of Raleigh et al. (2015) and Sauter and Obleitner (2015). The other errors of the forcing data, described in Morin et al. (2012), are neglected in this study as previously mentioned.

\subsection{Evaluation data}

Six variables were selected to evaluate ESCROC: snow depth (SD), snow water equivalent (SWE), bulk density (BD), surface broadband albedo (A), snow surface temperature (SST) and ground temperature at $50 \mathrm{~cm}$ depth (GT50). To eliminate the summer period without snow on the ground, the time series are limited to the period between 1 October and 30 June. The 0 values of SD and SWE between these two dates are kept for the evaluations to appropriately evaluate the formation and disappearance of the snowpack. BD, A and SST are not defined when there is no snow on the ground. For the six variables, Fig. 1 shows histograms of differences between distinct observations of the same variable in the experimental plot, which are used to quantify the uncertainty of each observed variable. Data observed at CDP since 2011 were sometimes used for observation error analysis but not for model forcing and evaluation.

\subsubsection{Snow depth (SD)}

Snow depth data from an ultrasound depth gauge span the whole winter from 1993 to 2010 and were completed by laser ranger data for the 2010-2011 winter. The instrumental error of these sensors (about $1 \mathrm{~cm}$ ) is low compared to the spatial variability of snow depth in the meadow. The latter was estimated by comparing ultrasound sensor data with weekly snow pit measurements at three different locations (Fig. 1a). The differences usually range between 0 and $20 \mathrm{~cm}$.

\subsubsection{Snow water equivalent (SWE)}

Snow water equivalent is measured on a daily basis by cosmic rays sensors (NRC) that are linearly calibrated every year to match weekly snow pit measurements (Gottardi et al., 2013). This time series has been available since 2001. The sensor accuracy (about $10 \%$ ) is of the same magnitude as the spatial variability in the meadow, which can be derived from snow pit data (Fig. 1b). A similar magnitude of uncertainty was found by Smith et al. (2016).

\subsubsection{Bulk density (BD)}

Although both SD and SWE automatic measurements are available daily since 2001 , their spatial variability in the meadow and therefore between the two sensor locations is too high to compute a robust daily time series of snow density, especially with shallow snow cover and during the melting season. For this reason, bulk density was computed from weekly snow pit measurements of SWE and SD. Figure 1c illustrates the uncertainty in this data resulting from its spatial variability (three snow pits on each date). The instrumental error of the snow core sampling is not well known. Proksch et al. (2016) give a magnitude of 1 to $5 \%$ for average density measurements errors with smaller cutters and a small number of data. Conger and McClung (2009) obtained an uncer- 

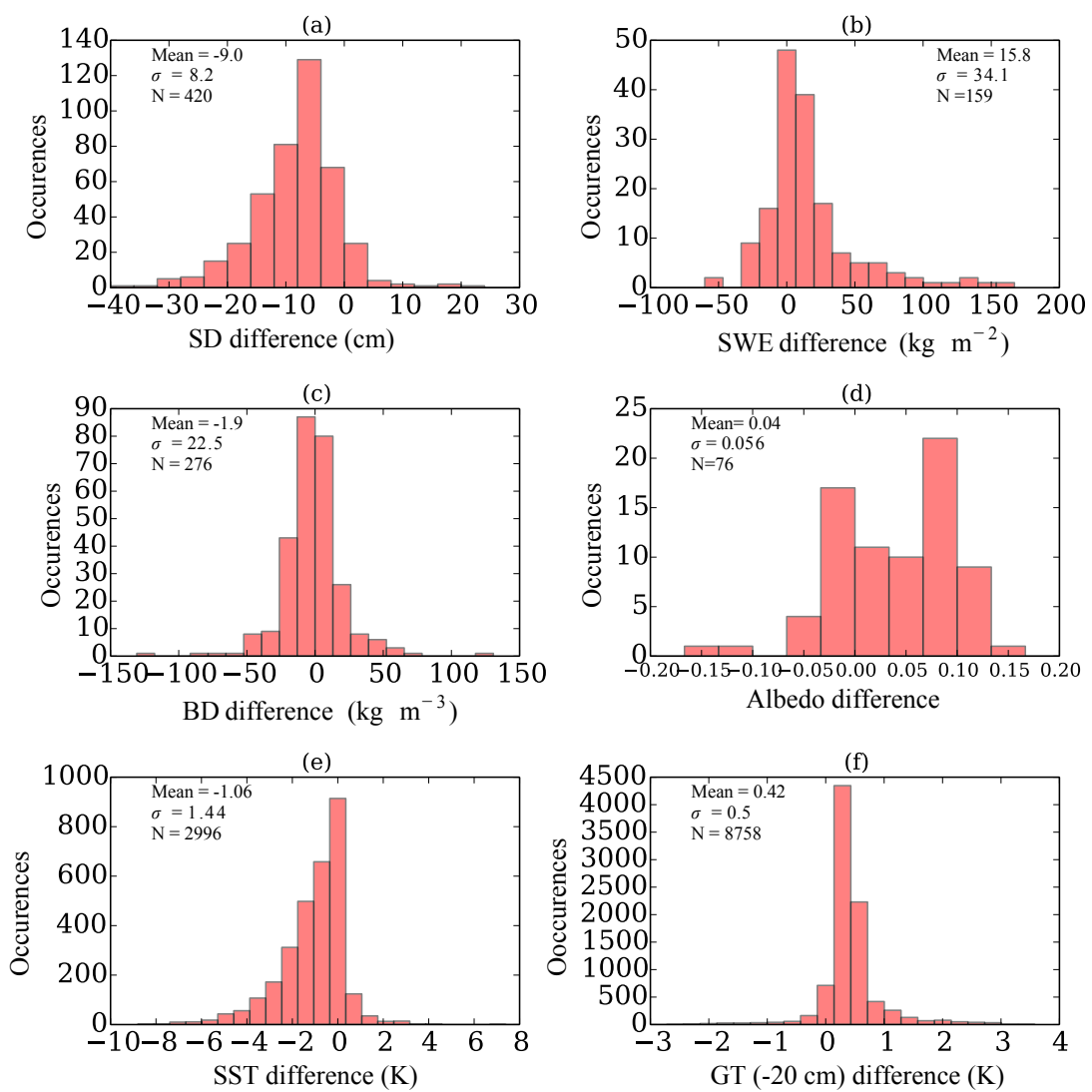

Figure 1. Distribution of differences between the reference observations and other sources of data: (a) snow depth (SD) automatic measurements vs. the three snow pits (2001-2011), (b) snow water equivalent (SWE) automatic measurements vs. the snow pit SWE measurements that are not used for sensor calibration (2001-2011), (c) bulk density (BD) from the reference snow pit vs. the other snow pits (2001-2011), (d) daily reference albedo vs. data from Dumont et al. (2016) (winter 2013-2014), (e) reference snow surface temperature (SST) vs. SST from the hemispheric pyrgeometer (1993-2010), (f) reference ground temperature (GT) at $-20 \mathrm{~cm}$ vs. measurements of a new sensor at the same depth (season 2013-2014).

tainty range of $2-11 \%$ for individual layer density measurements and emphasised that their accuracy depends on the cutter size. In the present study, the instrumental error of large cutters for bulk density is estimated to be roughly $10 \mathrm{~kg} \mathrm{~m}^{-3}$.

\subsubsection{Snow albedo (A)}

Daily broadband albedo was calculated from daily averaged downwelling and upwelling broadband shortwave radiation fluxes and is discarded during snowfall events, or when the measured fluxes are too low (Morin et al., 2012). Albedo data under 0.6 were also discarded in this work as they are evidence of patchy snow cover. The resulting data are rather discontinuous; however they span the entire 1993-2011 period. It is difficult to quantify the uncertainty of these data directly from the pyranometer manufacturer values. The uncertainty was estimated by comparing the data with broadband albedo data obtained from spectral measurements during the winter 2013-2014 (Dumont et al., 2016). The differences (Fig. 1d) originate from both the sensor errors and the spatial variabil- ity in the plot. They are quite high relative to the range of possible values for snow.

\subsubsection{Snow surface temperature (SST)}

Two values for the hourly mean snow surface temperature were derived separately from the upcoming longwave radiation and from an infrared sensor with a narrower angle of view, both assuming an emissivity of 1 for snow as described in Morin et al. (2012). An additional data treatment was performed to discard artefacts due to patchy snow covers or to a heating of the metal mast: temperatures exceeding the melting point of water, some outliers under $240 \mathrm{~K}$ and times where $\mathrm{A}<0.6$ or $\mathrm{SD}<0.3 \mathrm{~m}$ were removed from the time series. As this variable exhibits a high diurnal cycle, we decided to keep the 12:00 and 24:00 UTC temperature measurements in order to balance daytime and night-time values. The availability of two distinct long time series allows a quantification of the uncertainty in SST measurements re- 
sulting from both instrumental errors and spatial variability in the meadow (Fig. 1e).

\subsubsection{Ground temperature at $50 \mathrm{~cm}($ GT50)}

Ground temperature is recorded at three different depths $(-10,-20$ and $-50 \mathrm{~cm})$. Without snow, the diurnal cycle is very high close to the surface but it is not a key process in later simulating the heat flux at the interface with the snowpack, which is more affected by long-term biases. Therefore, we preferred to select the $50 \mathrm{~cm}$ depth for the evaluations. Only the October-December period was used for this variable as it is the key period for snowpack simulations. Spring and summer errors are much less important and ground temperature stays usually very close to $0^{\circ} \mathrm{C}$ between January and the end of the season. No other sensor provides temperature measurement at this depth. New sensors were, however, installed in October 2012, a few metres away at 5,10 and $20 \mathrm{~cm}$ depths. We assume that the differences between the sensors at $20 \mathrm{~cm}$ (Fig. 1f) provide an estimate of the magnitude of the uncertainty resulting from spatial variability and instrumental accuracy. The distance between sensors is probably too low but the spatial variability is expected to decrease with depth.

\section{The ESCROC multiphysical snow model}

The SURFEX/ISBA/Crocus unidimensional multilayer physical snowpack model is extensively described in Vionnet et al. (2012). It computes all terms of the energy and mass balance of the snowpack. In the standard version, the prognostic variables of each snow layer are mass, density, temperature, liquid water content, semi-empirical variables describing the snow microstructure and the layer age (as a proxy for the amount of impurities). The Lagrangian discretization rules are designed to accurately reproduce the snowpack stratigraphy evolution, a key component for avalanche forecasting. The heat flux at the ground-snow interface is simulated by a semi-implicit coupling with the multilayer ground model ISBA-DIF (Decharme et al., 2011).

In NWP ensemble modelling, two options are usually employed to disturb the model physics: stochastic perturbations of parameters (Palmer et al., 2009) or multiple combinations of several physical options, commonly called multiphysics (Charron et al., 2010; Descamps et al., 2014). In ESCROC, the multiphysics approach has been chosen. The ESCROC multiphysical ensemble is built implementing new physical options inside the SURFEX/ISBA/Crocus source code for the main physical processes, resulting in a "factorial" ensemble as in Essery et al. (2013). Several options implemented in the source code in previous studies (Carmagnola et al., 2014; Charrois et al., 2016) but not used in the standard version are incorporated in the ensemble. New options extracted from the literature and existing snowpack models such as SNOW-

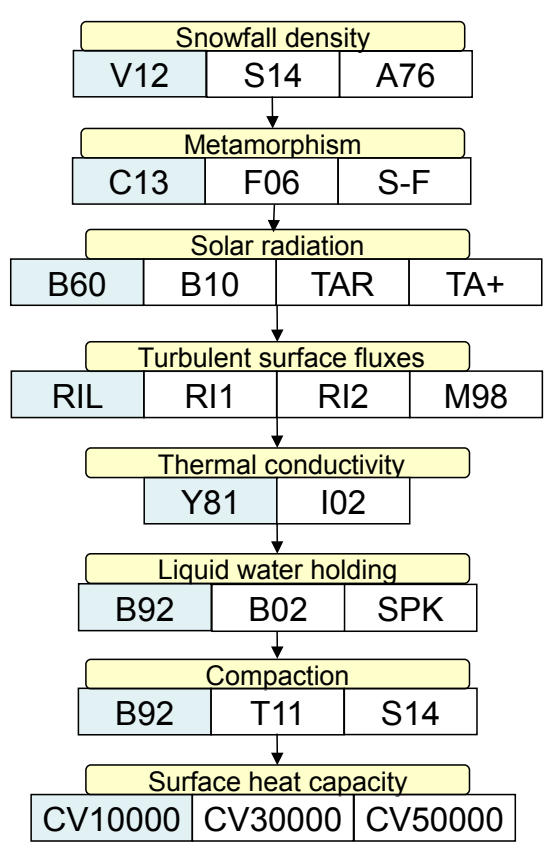

Figure 2. ESCROC physical options, blue cells correspond to the default Crocus configuration.

PACK or JIM were also implemented for other physical processes. Modifications of especially uncertain and sensitive parameters are also introduced for processes which do not have representations available in the literature that are able to sufficiently cover the uncertainty. The selected options for each process are summarised in Fig. 2 and detailed below.

\subsection{Fresh snow properties}

Crocus computes density and microstructural properties of falling snow from air temperature and wind speed during snowfall. Different laws are available in the literature for fresh snow density. All of them are empirical, relying on simultaneous measurements of wind speed and air temperature followed by manual measurements of freshly fallen snow density. The Crocus default option called V12 (Vionnet et al., 2012; Pahaut, 1975) computes density $\rho_{\mathrm{n}}$ from $2 \mathrm{~m}$ air temperature $T_{\mathrm{a}}\left(\right.$ in ${ }^{\circ} \mathrm{C}$ ) and $10 \mathrm{~m}$ wind speed $U\left(\mathrm{~m} \mathrm{~s}^{-1}\right)$ :

V12: $\rho_{\mathrm{n}}=\max \left(\rho_{\min }, a_{\rho}+b_{\rho} T_{\mathrm{a}}+c_{\rho} U\right)$.

The parameterisation of density from SNOWPACK (Schmucki et al., 2014), called S14 here, was also implemented. It also depends on wind speed and air temperature:

S14: $\left\{\begin{array}{l}\log _{10}\left(\rho_{\mathrm{n}}\right)=e_{\rho}+f_{\rho} T_{\mathrm{a}}+g_{\rho}+h_{\rho} \sin ^{-1}\left(\sqrt{i_{\rho}}\right) \\ +j_{\rho} \log _{10}(\max [U, 2]) \\ \text { if } T \geq-14^{\circ} C \\ \log _{10}\left(\rho_{\mathrm{n}}\right)=e_{\rho}+f_{\rho} T_{\mathrm{a}}+h_{\rho} \sin ^{-1}\left(\sqrt{i_{\rho}}\right) \\ +j_{\rho} \log _{10}(\max [U, 2]) \\ \text { otherwise }\end{array}\right.$ 
Table 1. Parameter values of fresh snow density options.

\begin{tabular}{ll}
\hline Option & Parameters \\
\hline V12 & $\rho_{\min }=50 \mathrm{~kg} \mathrm{~m}^{-3} ; a_{\rho}=109 \mathrm{~kg} \mathrm{~m}^{-3} ;$ \\
& $b_{\rho}=6 \mathrm{~kg} \mathrm{~m}^{-3} \mathrm{~K}^{-1} ; c_{\rho}=26 \mathrm{~kg} \mathrm{~m}^{-7 / 2} \mathrm{~s}^{-1 / 2} ;$ \\
& $d_{\rho}=8 \mathrm{~kg} \mathrm{~m}^{-3} \mathrm{~K}^{-1}$ \\
S14 & $e_{\rho}=3.28 ; f_{\rho}=0.03 \mathrm{~K}^{-1} ; g_{\rho}=-0.36 ;$ \\
& $h_{\rho}=-0.75 ; i_{\rho}=0.8 ; j_{\rho}=0.3$ \\
A76 & $\rho_{\min }=50 \mathrm{~kg} \mathrm{~m}^{-3} ; k_{\rho}=1.7 \mathrm{~K}^{-1} ; l_{\rho}=15 \mathrm{~K}$ \\
\hline
\end{tabular}

Finally, we implemented the law from Anderson (1976) in which the density only depends on air temperature:

$\mathrm{A} 76: \rho_{\mathrm{n}}=\rho_{\min }+\max \left(k_{\rho}\left(T_{\mathrm{a}}+l_{\rho}\right)^{1.5}, 0\right)$.

The parameters of the three laws are given in Table 1 and their behaviour is summarised in Fig. 3 .

The uncertainty associated with the initial microstructural properties is not included in ESCROC because the sensitivity of albedo (and in turn of the energy balance) to the specific surface area (SSA) of snow is low for typical values of fresh snow SSA usually above $40 \mathrm{~m}^{2} \mathrm{~kg}^{-1}$ (Gallet et al., 2009).

\subsection{Snow metamorphism}

The default Crocus representation of snow metamorphism (B92) describes the snow microstructure by a semiquantitative formalism with dendricity, sphericity and size (Brun et al., 1992). The time evolution of these continuous parameters follows empirical laws, the parameters of which were adjusted through experimental investigations. In the case of dry snow, these laws depend mostly on temperature and temperature gradient. For wet snow metamorphism, evolution laws only depend on liquid water content (Brun et al., 1989). An alternative formalism was introduced by Carmagnola et al. (2014), who replaced dendricity and size by the optical diameter, which is measurable in the field. However, as the formalism is a translation of B92 laws with new prognostic variables, using both formulations is almost equivalent and not able to describe the uncertainty associated with this process. Therefore, only the C13 option is included in ESCROC. We also included the time evolution law of the optical diameter from Flanner and Zender (2006), which fits the model outputs of a snow microstructure model representing the diffusive vapour fluxes among the grains (F06). This law was also implemented by Carmagnola et al. (2014), who found that its skill was similar to the $\mathrm{C} 13$ formulation. Note that this option does not affect wet metamorphism, which still follows the original formulation of Brun et al. (1989).

We also implemented the formulation of Schleef et al. (2014), who focused on the first $48 \mathrm{~h}$ after snowfall and proposed the following law experimentally calibrated under

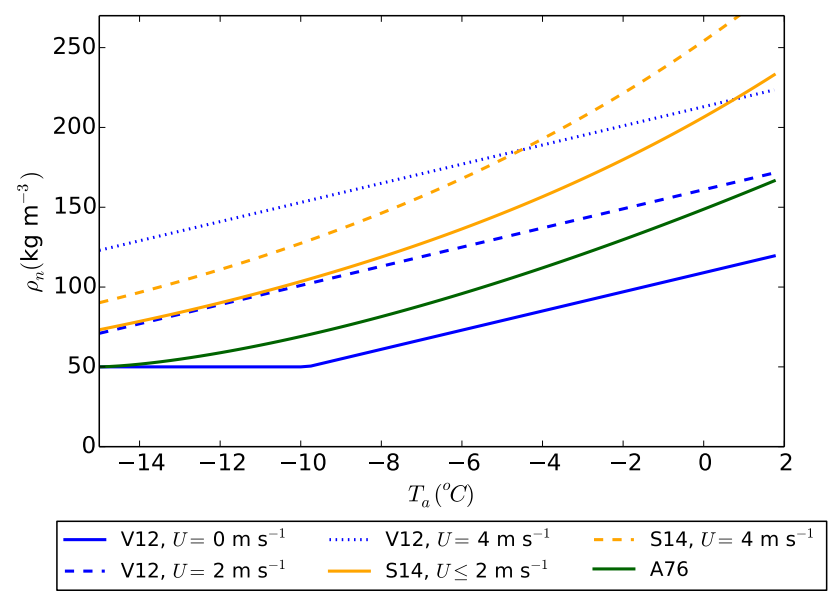

Figure 3. Fresh snow density as a function of air temperature and wind for the 3 options included in ESCROC.

isothermal conditions:

$\frac{\mathrm{dSSA}}{\mathrm{d} t}=(a+b T) \mathrm{SSA}^{m}$,

with $a=1.1 \times 10^{-6}, b=3.1 \times 10^{-8}$ and $m=3.1$.

As this formulation only applies to the first $48 \mathrm{~h}$, we chose to associate this option with the F06 evolution law for older snow (option S-F).

\subsection{Blowing snow and associated sublimation}

Wind-induced snow transport drift is a complex phenomenon known to be a key factor for slab avalanches as it creates local snow accumulation and has an effect on metamorphism by reducing the grain size, compacting the top layers and increasing their cohesion. Sublimation of snow particles in turbulent suspension is frequent during blowing snow events. A scheme to represent erosion and accumulation on the different aspects of idealised slopes can be activated in Crocus (Durand et al., 2001). For more general applications in which erosion and accumulation cannot be simulated by a unidimensional model, Vionnet et al. (2012) introduced a parameterisation to modify the physical properties in near-surface snow layers during blowing events and to optionally simulate mass loss due to blowing snow drift. Although these options can be very sensitive in windy environments (Libois et al., 2015), we decided to deactivate them for the first version of ESCROC because it is not possible to evaluate the uncertainty of this process at CDP where blowing snow is almost never observed.

\subsection{Solar radiation absorption}

The original formulation of radiative transfer in the snowpack (Brun et al., 1992) consists of computing solar radiation absorption and reflection in three spectral bands $(0.3-0.8$; $0.8-1.5$ and $1.5-2.8 \mu \mathrm{m}$ ) and is partly inspired from the work 
Table 2. Parameter values for solar radiation absorption options.

\begin{tabular}{|c|c|}
\hline Option & Parameters \\
\hline B60 & $\tau_{\mathrm{a}}=60$ days \\
\hline B10 & $\tau_{\mathrm{a}}=10$ days \\
\hline TAR & $\begin{array}{l}c_{0}=5 \mathrm{ng} \mathrm{g}^{-1} ; \tau_{0}=4 \mathrm{ng} \mathrm{g}^{-1} \mathrm{day}^{-1} \\
l_{\mathrm{f}}=0.05 \mathrm{~m}\end{array}$ \\
\hline $\mathrm{TA}+$ & $\begin{array}{l}c_{0}=50 \mathrm{ng} \mathrm{g}^{-1} ; \tau_{0}=200 \mathrm{ng} \mathrm{g}^{-1} \text { day }^{-1} ; \\
l_{\mathrm{f}}=0.05 \mathrm{~m}\end{array}$ \\
\hline
\end{tabular}

of Warren (1982). Only the grain characteristics of the two uppermost numerical layers are used to compute the albedo of each spectral band. A parameterisation reduces the albedo in the visible band as a function of the age of the layer and the altitude of the site to mimic the effect of light-absorbing impurities. This parameterisation relies on a time constant $\tau_{\mathrm{a}}$ usually taken as 60 days at midlatitudes (option B60). At CDP, this value is suspected of partially explaining a positive bias in Crocus-simulated albedo. Therefore, we define the B10 option by using a 10-day value.

The radiative transfer scheme TARTES (Two-streAm Radiative TransfEr in Snow, Libois, 2014) has recently been implemented in Crocus (and used by Libois et al., 2015 and Charrois et al., 2016). It simulates the absorption of solar radiation within the stratified snowpack using the $\delta$-Eddington approximation and with a spectral resolution of $20 \mathrm{~nm}$. This scheme explicitly accounts for the spectral and angular characteristics of the incident radiance (e.g. the solar zenith angle and the presence of a cloud cover) and uses an explicit impurity content for each layer (equivalent black carbon content). The impurity content $c$ is initialised to a constant concentration $c_{0}$ during snowfall. A dry deposition term $\tau_{\mathrm{dd}}$ is added to the layer at depth $D$ at each time step:

$\tau_{\mathrm{dd}}=\tau_{0} e^{-D / l_{\mathrm{f}}}$.

This formulation and its parameters are rather uncertain as they have not been specifically evaluated against observations. While the simulations are weakly sensitive to the efolding depth $l_{\mathrm{f}}$, the simulated albedo highly depends on the velocity of impurities deposition. The typical magnitude of the parameters for black carbon only would be $c_{0}=5 \mathrm{ng} \mathrm{g}^{-1}$ and $\tau_{0}=4 \mathrm{ng} \mathrm{g}^{-1}$ according to Doherty et al. (2013) or Sterle et al. (2013) (option TAR), but values 20 times as high were sometimes observed. Furthermore, as other impurities such as dust and vegetal debris are not explicitly accounted for, higher values of the parameters are possible to indirectly simulate the effect of these species with their black-carbon equivalent concentrations. We included in ESCROC two different sets of parameters for this physical scheme (TAR and $\mathrm{TA}+$ ). The four resulting options for solar radiation absorption are summarised in Table 2.
Table 3. Parameter values for turbulent surface fluxes options.

\begin{tabular}{ll}
\hline Option & Parameters \\
\hline RIL & $R i_{1}=0.2 ; z_{0}=10^{-3} \mathrm{~m} ; z_{0 h}=10^{-4} \mathrm{~m}$ \\
RI1 & $R i_{1}=0.1 ; z_{0}=10^{-3} \mathrm{~m} ; z_{0 h}=10^{-4} \mathrm{~m}$ \\
RI2 & $R i_{1}=0.026 ; z_{0}=10^{-3} \mathrm{~m} ; z_{0 h}=10^{-4} \mathrm{~m}$ \\
M98 & $R i_{1}=0.026 ; z_{0}=10^{-3} \mathrm{~m} ; z_{0 h}=10^{-3} \mathrm{~m}$ \\
\hline
\end{tabular}

\subsection{Turbulent fluxes}

As detailed in Vionnet et al. (2012), Crocus surface turbulent fluxes (latent heat flux LE and sensible heat flux $H$ ) are proportional to the turbulent exchange coefficient or drag coefficient $C_{H} . C_{H}$ depends on the Richardson number $R i$, which quantifies the stability of the atmosphere directly above the snow surface, and on the effective roughness length for momentum $z_{0}$ and for heat $z_{0 h}$ (Louis, 1979; Noilhan and Mahfouf, 1996). In particular, $C_{H}$ decreases when $R i$ increases (Fig. 4), and the rougher the surface, the higher the fluxes. The Louis parameterisation tends to minimise surface heat fluxes under stable conditions $(R i>0)$ but in mountainous terrain with complex topography, mechanical or orographicinduced turbulence is suspected of producing exchange rates higher than in this theory. For this reason, in Crocus Martin and Lejeune (1998) proposed to apply a threshold $R i_{1}=$ 0.026 on the Richardson number to maintain a minimal level of turbulence in stable conditions:

$C_{H}\left(R i \geq R i_{1}\right)=C_{H}\left(R i_{1}\right)$.

They also applied an effective roughness length for heat supposed to be closer to the roughness length for momentum than usual values for snow (option M98).

In the current default version of the model (RIL), Vionnet et al. (2012) chose the formulation of the ISBA-ES snow scheme (Boone and Etchevers, 2001), already included in the SURFEX platform, where $R i_{1}$ is taken as 0.2 and $z_{0 h}$ as $10^{-4} \mathrm{~m}$. As preliminary studies showed that both configurations simulate turbulent fluxes of different magnitude, we address the uncertainty in ESCROC also using two intermediate configurations (RI1 and RI2) as summarised in Table 3 and Fig. 4.

\subsection{Thermal conductivity}

Snow thermal conductivity $\lambda$ mostly depends on snow density $\rho_{\mathrm{s}}\left(\mathrm{kg} \mathrm{m}^{-3}\right)$ (Calonne et al., 2011). Two different options were already implemented in Crocus. The default option follows Yen (1981) (Y81):

$\mathrm{Y} 81: \lambda=\max \left[a_{\lambda}\left(\frac{\rho_{\mathrm{S}}}{\rho_{\mathrm{W}}}\right)^{1.88} ; \lambda_{\min }\right]$.

$\rho_{\mathrm{W}}$ is the liquid water density $\left(\mathrm{kg} \mathrm{m}^{-3}\right)$. This formulation is very close to the experimental law proposed by Calonne et al. (2011) based on tomographic images of snow (Fig. 5). 


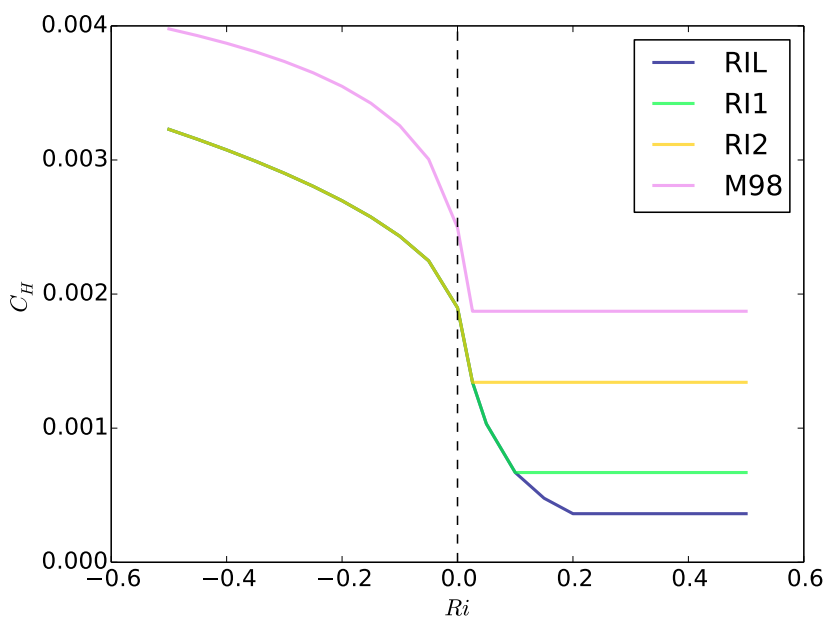

Figure 4. $C_{H}$ as a function of $R i$ for the four turbulent fluxes options included in ESCROC (RIL, RI1, RI2, M98) as summarised in Table 3.

Table 4. Parameter values for thermal conductivity options.

\begin{tabular}{ll}
\hline Option & Parameters \\
\hline Y81 & $a_{\lambda}=2.22 \mathrm{~W} \mathrm{~m}^{-1} \mathrm{~K}^{-1} ;$ \\
& $\lambda_{\min }=4 \times 10^{-2} \mathrm{~W} \mathrm{~m}^{-1} \mathrm{~K}^{-1}$ \\
$\mathrm{I} 02$ & $e_{\lambda}=2.0 \times 10^{-2} \mathrm{~W} \mathrm{~m}^{-1} \mathrm{~K}^{-1} ;$ \\
& $f_{\lambda}=2.5 \times 10^{-6} \mathrm{~W} \mathrm{~m}^{5} \mathrm{~K}^{-1} \mathrm{~kg}^{-2}$ \\
& $g_{\lambda}=-6.023 \times 10^{-2} \mathrm{~W} \mathrm{~m}^{-1} \mathrm{~K}^{-1} ;$ \\
& $h_{\lambda}=-2.5425 \mathrm{~W} \mathrm{~m}^{-1}$ \\
& $i_{\lambda}=-289.99 \mathrm{~K} ; P^{0}=10^{5} \mathrm{~Pa}$ \\
\hline
\end{tabular}

The other implemented option, I02, is the default formulation of the ISBA-ES snow model (Boone, 2002; Sun et al., 1999):

$\mathrm{I} 02: \lambda=e_{\lambda}+f_{\lambda} \rho_{\mathrm{s}}^{2}+\left(g_{\lambda}+\frac{h_{\lambda}}{T+i_{\lambda}}\right) \frac{P^{0}}{P}$.

$P$ is the atmospheric pressure $(\mathrm{Pa})$ and parameter values are given in Table 4 . The I02 law depends not only on density but also on snow temperature and it has a higher conductivity than experimental values (Fig. 5) to indirectly compensate for the fact that latent heat fluxes due to vapour fluxes are not represented in Crocus. This is expected to increase vertical heat transfer as temperature increases.

\subsection{Liquid water content}

Liquid water content is an important variable for its role in metamorphism, thermal exchanges due to phase changes, compaction and mechanical stability. However, it is especially challenging to both observe and simulate liquid water percolation in the snowpack, particularly because its horizontal variability is very high at macroscopic scale. Work is in progress to include in Crocus a formulation solving Richards

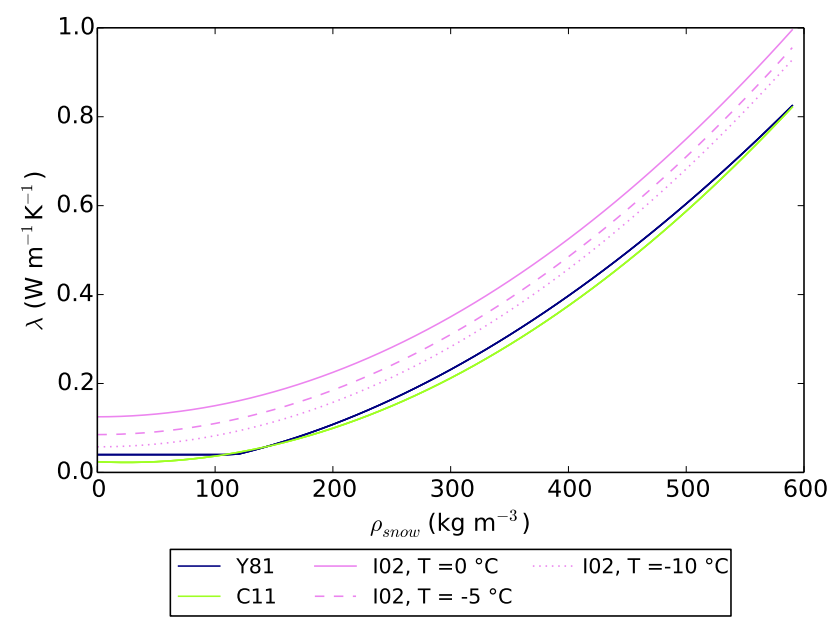

Figure 5. Snow thermal conductivity as a function of density for the two options included in ESCROC (Y81, I02), and for the experimental law proposed by Calonne et al. (2011) (C11).

equations in snow as in Wever et al. (2014) and D'Amboise et al. (2017). However, the only formulation currently available for the liquid water percolation in the snowpack follows a simple and conceptual bucket approach in which the layers are seen as superposed water reservoirs with a homogeneous volumetric liquid water content $w_{\text {liq }}$ in $\mathrm{kg} \mathrm{m}^{-3}$. When $w_{\text {liq }}$ exceeds the maximum liquid water-holding capacity $w_{\text {liq, max }}$, the excess water drains to the underlying layer.

In the default version of Crocus (B92 option), the volumetric liquid water-holding capacity is defined by a fixed maximal percentage of the pores' volumes (Pahaut, 1975):

B92: $w_{\text {liq, } \max }=0.05 \rho_{\mathrm{w}} \phi$,

where $\phi=1-\frac{\rho-w_{\text {liq }}}{\rho_{\mathrm{i}}}$ is the snow porosity and $\rho_{\mathrm{i}}$

the pure ice density $\left(\mathrm{kg} \mathrm{m}^{-3}\right)$.

Equations (9) and 10) should replace the formulas with typos given in Vionnet et al. (2012) and in Gascon et al. (2014). As a result, the higher the density the lower the maximal volumetric liquid water content.

The experiments of Coléou and Lesaffre (1998) give water-holding capacities about $40 \%$ higher than B92 formulation as shown in Fig. 6. There was also a typo in the equation of that paper, corrected in Eq. (11).

C98: $w_{\text {liq } \max }=\rho \times\left(0.057 \frac{\phi}{1-\phi}+0.017\right)$

Based on this finding, a similar formulation was chosen for the bucket version of the SNOWPACK model. Equation (12) replaces Eq. (1) of Wever et al. (2014) where there is a typo 
in the conditions:

$\mathrm{SPK}: \begin{cases}w_{\text {liq }, \max }=\rho_{\mathrm{w}} & \times(0.08-0.1023(0.97-\phi)) \\ & \text { if } \phi \geq 0.77 \\ w_{\text {liq, } \max }=\rho_{\mathrm{w}} & \times\left(0.0264+0.0099 \frac{\phi}{1-\phi}\right) \\ & \text { otherwise }\end{cases}$

This option was also included in ESCROC (SPK).

In several other models (Essery et al., 2013), the water retention capacity is defined by a maximal liquid water mass fraction. We included the ISBA-ES formulation (B02, Boone, 2002) in ESCROC for which this threshold is set to $r_{\text {min }}=0.03$ for snow densities above $\rho_{r}=200 \mathrm{~kg} \mathrm{~m}^{-3}$ and to higher values up to 0.05 for very low density, following

B02: $w_{\text {liq, } \max }=$

$\frac{\rho}{\rho_{\mathrm{W}}}\left(r_{\min }+\left(r_{\max }-r_{\min }\right) \max \left(0, \frac{\rho_{\mathrm{r}}-\rho}{\rho_{\mathrm{r}}}\right)\right)$,

where $r_{\max }=0.1$.

This formulation displays the opposite behaviour: the higher the density, the higher the maximal volumetric liquid water content (Fig. 6). The discrepancies between B02 and B92/SPK options increase for low densities. Although such behaviour is not consistent with laboratory experiments of Coléou and Lesaffre (1998), including this formulation in ESCROC allows us to very indirectly account for the uncertainty linked to the heterogeneous percolation of liquid water. The latter result in the presence of wet layers below layers which are not homogeneously saturated, increasing the percolation velocity. Note that liquid water percolation is also affected by capillary effects and by a high dependence of snow permeability on the structure of the pores as reported by Jordan et al. (1999) or Calonne et al. (2012). As these processes cannot be described by the bucket approach used in Crocus, it is reasonable to include a wide uncertainty for low densities in ESCROC through the use of these three different formulations.

\subsection{Compaction}

For a given layer of thickness $D$ the settling under the over burden $\sigma$ is expressed as follows (Anderson, 1976; Navarre, 1975):

$\frac{\mathrm{d} D}{D}=\frac{-\sigma}{\eta} \mathrm{d} t$

The viscosity $\eta$ is expressed as a function of density $\rho$ and temperature $T\left({ }^{\circ} \mathrm{C}\right)$ by

B92: $\eta=f_{1}\left(w_{\text {liq }}\right) f_{2}\left(g_{\mathrm{s}}\right) \eta_{0} \frac{\rho}{c_{\eta}} e^{a_{\eta}(-T)+b_{\eta} \rho}$,

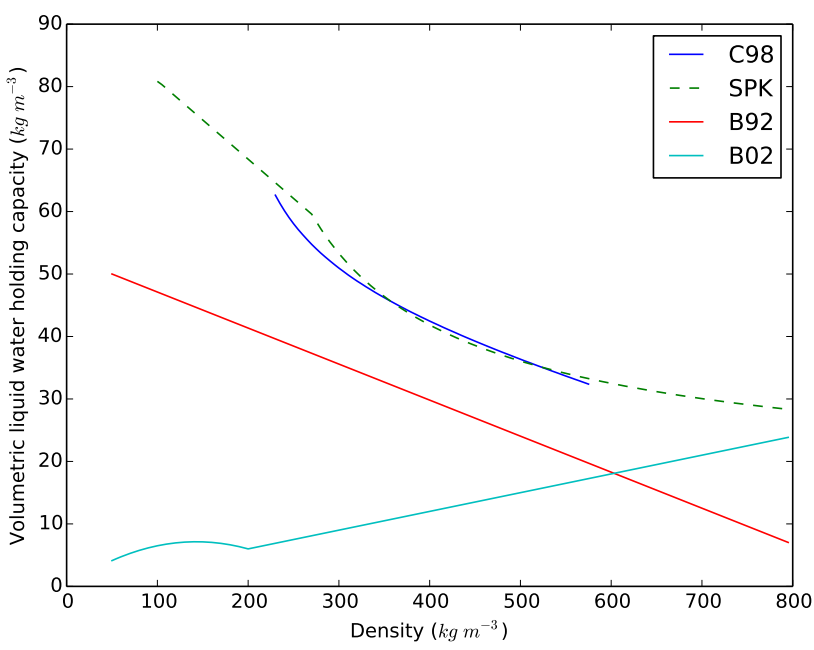

Figure 6. Volumetric liquid water-holding capacity as a function of the layer density for the three options included in ESCROC (B92, SPK, B02) and for the experimental law proposed by Coléou and Lesaffre (1998) (C98).

where $\eta_{0}=7.62237 \times 10^{6} \mathrm{~kg} \mathrm{~s}^{-1} \mathrm{~m}^{-1}, a_{\eta}=0.1 \mathrm{~K}^{-1}, b_{\eta}=$ $0.023 \mathrm{~m}^{3} \mathrm{~kg}^{-1}$ and $c_{\eta}=250 \mathrm{~kg} \mathrm{~m}^{-3}$. Two multiplicative functions $f_{1}$ and $f_{2}$ represent the faster settlement of wet snow as a function of the volumetric liquid water content $w_{\text {liq }}$, and the reduced settlement of layers consisting of faceted snow types, especially depth hoar as a function of grain size $g_{\mathrm{s}}$ (Vionnet et al., 2012).

However, the temperature and density dependence of snow viscosity have various forms in the literature as reviewed by Teufelsbauer (2011), who proposed a new law fitting the data of separate experimental works. If this law is combined with Crocus parameterisation for wet snow and depth hoar, we can formulate a new option T11 as

$\mathrm{T} 11: \eta=$

$f_{1}\left(w_{\text {liq }}\right) f_{2}\left(g_{\mathrm{s}}\right) \times 0.05 \rho^{-0.0371 T+4.4}\left(10^{-4} e^{0.018 \rho}+1\right)$.

The compaction velocity, however, has a complex dependence to snow microstructure (Lehning et al., 2002) which cannot be described by the representation of snow microstructure in Crocus. We account for this source of uncertainty by implementing the S14 option, in which we apply a non-linear relationship between settlement, the stress $\sigma(\mathrm{Pa})$ and the SSA decrease from Schleef et al. (2014) for the first $48 \mathrm{~h}$ after snowfall:

$\mathrm{S} 14: \frac{\mathrm{d} \rho}{\mathrm{d} t}=B \rho \frac{\mathrm{dSSA}}{\mathrm{d} t} \sigma^{k}$

with $B=-6.6 \times 10^{-3}$ and $k=0.18$. The current Crocus parameterisation is applied when the snow layer age exceeds 2 days. 


\subsection{Soil scheme}

The conductive heat flux at the soil-snow interface depends on the temperature gradient between the snow bottom and the upper soil layer. It is explicitly modelled by a semi-implicit soil-snow coupling with one of the ISBA soil scheme options. Although several options are available in the SURFEX platform (Masson et al., 2013), the multilayer diffusive approach [ISBA-DIF] (Decharme et al., 2011, 2013) is preferred to force-restore options (Noilhan and Mahfouf, 1996), which are not able to represent the seasonal heat storage in the deep soil and therefore a realistic heat flux at the soilsnow interface (Habets et al., 2003). Generally, the uncertainties in soil modelling come from both the representation of physical processes and the soil texture and vegetation parameters. Their comprehensive exploration would represent a full extended new work beyond the scope of this paper. Sensitivity tests suggested that one of the most sensitive parameters on snow simulations is the surface heat capacity $c_{T}$ $\left(\mathrm{J} \mathrm{m}^{-2} \mathrm{~K}^{-1}\right)$ used in the soil surface temperature $T_{\mathrm{S}}$ prognostic equation:

$$
\frac{\partial T_{\mathrm{S}}}{\partial t}=\frac{1}{c_{T}} G-\frac{1}{c_{G_{1}}} \frac{\lambda_{1}}{\Delta z_{1}}\left(T_{\mathrm{S}}-T_{2}\right),
$$

where $G$ is the sum of radiative and turbulent energy fluxes at the surface $\left(\mathrm{W} \mathrm{m}^{-2}\right), \lambda_{1}$ the thermal conductivity of the first soil layer $\left(\mathrm{W} \mathrm{m}^{-1} \mathrm{~K}^{-1}\right), \Delta z_{1}$ its thickness $(0.01 \mathrm{~m}), c_{G_{1}}$ its heat capacity $\left(\mathrm{J} \mathrm{m}^{-2} \mathrm{~K}^{-1}\right)$ depending on its water content, and $T_{2}$ the temperature of the second soil layer. Equation (18) corresponds to the case without soil freezing or thawing which are also represented in the model (Decharme et al., 2016). For the CDP grassy meadow, the surface heat capacity is equal to the vegetation heat capacity $c_{\mathrm{V}}$. The default value of $c_{\mathrm{V}}$ has been set to $5 \times 10^{4} \mathrm{~J} \mathrm{~m}^{-2} \mathrm{~K}^{-1}$ since the 1990s for numerical stability reasons in the coupling with NWP models but this is unrealistic when compared with values from the literature (Dupont et al., 2014). In the v8.0 SURFEX release (http://www.umr-cnrm.fr/surfex//spip.php?rubrique148), the current default value has been set to $10^{4} \mathrm{~J} \mathrm{~m}^{-2} \mathrm{~K}^{-1}$ for lowlying vegetation. Although more realistic, at $\mathrm{Col}$ de Porte this value gives a significant cold bias in autumn, regardless of the snow scheme used, as illustrated by Fig. 5 of Decharme et al. (2016). In ESCROC, we account for the uncertainty in the soil-snow heat flux by including three different values of the vegetation heat capacity: $10^{4}, 3 \times 10^{4}$ and $5 \times 10^{4} \mathrm{~J} \mathrm{~m}^{-2} \mathrm{~K}^{-1}$. However, we must keep in mind that this unrealistic range probably compensates other model errors.

\section{Evaluation methodology}

\subsection{Individual scores of all members}

Although all ESCROC options are supposed to represent the corresponding physical processes with an equivalent complexity and reliability, it is necessary to check whether each combination of options has a satisfactory overall skill or if some of them should be eliminated. The skill of each single member is evaluated by deterministic scores comparing $N_{i}$ simulated values $m_{k_{i}}$ by member $i$ to the corresponding $N_{i}$ observations $o_{k}$. Note that $N_{i}$ depends on the observations availability which is specific to each evaluation variable (Sect. 2.2). Furthermore, for variables which are not defined when there is no snow on the ground (BD, SST, A), $N_{i}$ is specific to each member $i$ due to the variable duration of the snow season between members. We compute the bias estimator, $\widehat{B}_{i}$, and the root mean square error estimator, $\widehat{\mathrm{RMSE}}_{i}$ :

$$
\begin{aligned}
& \widehat{B_{i}}=\frac{1}{N_{i}} \sum_{k=1}^{N_{i}}\left(m_{k_{i}}-o_{k}\right) \\
& \widehat{\operatorname{RMSE}}_{i}=\sqrt{\frac{1}{N_{i}} \sum_{k=1}^{N_{i}}\left(m_{k_{i}}-o_{k}\right)^{2} .}
\end{aligned}
$$

These scores are called estimators because they give an uncertain description of the true model skill for several reasons. First, the reference observations $o_{k}$ represent an uncertain description of the site-scale snow conditions due to both instrumental errors and spatial variability at the site. Then, the skill of a member with respect to observations has a significant variability from one season to another so that uncertainty is associated with the limited available evaluation period. To account for these uncertainties, we model a member score $S_{i}$ as a random variable following a normal distribution $\mathcal{N}\left(\widehat{S_{i}}, \widehat{\sigma_{i}}\right)$, where the total variance is decomposed by $\widehat{\sigma_{i}^{2}}=\sigma_{\mathrm{o}}^{2}+\sigma_{p_{i}}^{2}$. To quantify the $\sigma_{p_{i}}$ component corresponding to the evaluation period uncertainty, we applied bootstrapping (Efron, 1979) over annual time series on each variable: for each member, instead of computing only one score for the available years (1993-1994, 1994-1995, 1995-1996, ..., 2010-2011), 1000 different score estimators were computed from 1000 18-year-long bootstrap samples obtained by draw with replacement of the available years such as 1998-1999, 1994-1995, 1994-1995, .., 2003-2004. $\sigma_{p_{i}}$ is the standard deviation of these estimators. Generally, the observation uncertainty $\sigma_{\mathrm{o}}$ is difficult to quantify without a large range of sensors measuring instrumental uncertainty and spatial uncertainty and it is often necessary to choose a priori values. In this study, for SD, SWE, albedo, SST and GT, the mean and the standard deviation of the differences between the reference observation and other data from another instrument located at another place in the plot (Sect. 2.2, Fig. 1) allow an estimate of $\sigma_{\mathrm{o}}$ for the bias and the RMSE to be given. For BD, the estimated instrumental error has to be added to the spatial uncertainty shown in Fig. 1c. The values of $\sigma_{\mathrm{o}}$ are summarised in Table 5.

With the assumption of a Gaussian distribution of the score, it is possible to compute its $90 \%$ confidence interval and to test the significance of the difference between two different members by a Student test. Note that this Gaussian 
Table 5. Values of $\sigma_{\mathrm{o}}$ for the bias and the RMSE resulting from Sect. 2.2.

\begin{tabular}{lrr}
\hline Variable & $\sigma_{\mathrm{o}}$ for bias & $\sigma_{\mathrm{o}}$ for RMSE \\
\hline $\mathrm{SD}(\mathrm{cm})$ & 9.0 & 12.2 \\
$\mathrm{SWE}\left(\mathrm{kg} \mathrm{m}^{-2}\right)$ & 16 & 38 \\
$\mathrm{BD}\left(\mathrm{kg} \mathrm{m}^{-3}\right)$ & 10 & 26.5 \\
Albedo & 0.040 & 0.069 \\
$\mathrm{SST}(\mathrm{K})$ & 1.07 & 1.44 \\
GT50 $(\mathrm{K})$ & 0.42 & 0.50 \\
\hline
\end{tabular}

approximation is not realistic for RMSE but the high uncertainty of $\sigma_{\mathrm{o}}$ estimates do not justify proposing a more sophisticated error modelling.

This methodology is applied for each evaluated variable listed in Sect. 2.2. For SD, it is also applied separately for early snow depth (October-January) and late snow depth (from the date of observed maximum SWE to the end of the season) because the absence of bias in any part of the snow season is also required for a member to be considered satisfactory.

\subsection{Ensemble scores}

The skill of the ensemble of population $n$ can be assessed both by deterministic scores applied to the ensemble mean $\bar{E}$ and by probabilistic scores describing the spread and the ability of the ensemble to compute reliable probabilities. $\bar{E}$ is defined for each date $k$ as the mean of the $p_{k} \leq n$ available members $\left(m_{k_{i}}\right)_{i \in\left[1, p_{k}\right]}$ (Eq. 21). This restriction is necessary when computing scores on model variables that are not defined when there is no snow on the ground (BD, SST, A). For example, at the end of the snow season, when not all members have melted yet, the BD ensemble mean will be considered as the $\mathrm{BD}$ mean of the members that still have snow.

$\bar{E}_{k}=\frac{1}{p_{k}} \sum_{i=1}^{p_{k}} m_{k_{i}}$

The RMSE of an ensemble corresponds to the RMSE of the ensemble mean $\bar{E}$ over the $N$ dates where observations are available and at least one member is defined.

$\operatorname{RMSE}(\bar{E})=\sqrt{\frac{1}{N} \sum_{k=1}^{N}\left(\bar{E}_{k}-o_{k}\right)^{2}}$

The ensemble spread or dispersion $\sigma_{E}$ is the standard deviation of members relative to the ensemble average:

$\sigma_{E}=\sqrt{\frac{1}{N} \sum_{k=1}^{N} \frac{1}{p_{k}} \sum_{i=1}^{p_{k}}\left(m_{k_{i}}-\bar{E}_{k}\right)^{2} .}$
The spread-skill (SS) of the ensemble $E$ of mean $\bar{E}$ is then defined as follows:

$\mathrm{SS}=\frac{\sigma_{E}}{\operatorname{RMSE}(\bar{E})}$.

The ensemble dispersion is optimal if SS $=1$ (Fortin et al., 2014). In that case, the spread of the ensemble is representative of the error of the mean, and for an unbiased system, observations will mostly be inside the ensemble envelope.

The continuous ranked probability score (CRPS) is one of the most common probabilistic tools used to evaluate the ensemble skill, both in terms of reliability (unbiased probabilities) and resolution (ability to separate the probability classes) (Candille and Talagrand, 2005):

CRPS $=\frac{1}{N} \sum_{k=1}^{N} \int_{\mathbb{R}}\left(F_{k}(x)-H\left(x-o_{k}\right)\right)^{2} \mathrm{~d} x$,

where $F_{k}(x)$ is the cumulative distribution function of the ensemble simulation at time $k$ and $H(y)$ is the Heaviside function $(H(y)=0$ if $y \leq 0 ; H(y)=1$ if $y>0)$. CRPS value has the same unit as the evaluated variable and tends towards 0 for a perfect system. It is mainly useful to compare the overall skill of several ensembles. A skill score (CRPSS) can be defined to compare the CRPS of an ensemble $E$ to a reference $R$ :

$\operatorname{CRPSS}(E)=1-\frac{\operatorname{CRPS}(E)}{\operatorname{CRPS}(R)}$.

To compare the skill of a multiphysics ensemble simulation to the more classical deterministic snow modelling, we choose a single member for the reference $R$. In such a case, the CRPS reduces to the mean absolute error of the deterministic simulation. As the standard Crocus configuration (blue options in Fig. 2) is not optimal at Col de Porte, we choose the member with CV30000 surface heat capacity option and default other options as reference. This configuration has a better overall skill.

We also used rank histograms (Hamill, 2001) which illustrate the occurrence frequency of the different possible ranks of the observations $o_{k}$ among the sorted ensemble members. The flatness of this histogram is a condition of the system reliability (if the simulated probabilities are unbiased regardless of the probability level, the different ranks should have a uniform occurrence frequency). It is also an indicator of the spread-skill as underdispersion will result in a U-shaped rank histogram and overdispersion in a bell-shaped rank histogram.

Note that SS, CRPS and rank histograms are also affected by observations uncertainties similarly to deterministic scores. As a first step, this uncertainty is not modelled here but this lack should be kept in mind in the comparison of different ensembles. 


\subsection{Members selection methods}

As equiprobability of members is preferred in ensemble forecasting and ensemble assimilation applications, we extracted a sub-ensemble of $n$ equiprobable members, i.e. without a significantly lower skill than other members on any of the eight evaluation variables. We first selected this subensemble $E_{1}$ based on the deterministic evaluation of all ESCROC members described in Sect. 4.1 and evaluated its ensemble skill as described in Sect. 4.2 for five evaluation variables (SD, SWE, BD, A, SST). GT50 is not included for this evaluation step because ESCROC does not include a comprehensive description of uncertainty in soil modelling.

Then, among these equiprobable members, it is useful to limit the number of members $n^{\prime}$ to keep reasonable computing times in larger scale applications, and it may be possible to improve the spread-skill by selecting only some members since many configurations are highly correlated. We consider here that the value of $n^{\prime}$ is prescribed as a technical constraint. For illustration, we take $n^{\prime}=35$ as in Vernay et al. (2015). Many possible criteria can be defined to select these $n^{\prime}$ members. Here, we chose to present two selections based on the optimisation of the spread-skill for snow depth (ensemble $E_{2}$ ) and of the CRPS for snow depth (ensemble $\left.E_{3}\right)$. Other criteria might be better suited for specific applications and it would also be possible to define a multivariate criteria. In any case, the number of possible combinations $C_{n}^{n^{\prime}}=\frac{n !}{n^{\prime} !\left(n-n^{\prime}\right) !}$ can be huge when $n \gg n^{\prime}$ and testing all the possible ensembles can become unrealistic. In such a case, we propose to test the optimisation criteria (SS or CRPS here) randomly among 10000 combinations, and to evaluate the obtained sub-ensembles $E_{2}$ and $E_{3}$. The solution will obviously be neither absolute nor unique. If the dispersion of the $E_{1}$ full ensemble of equiprobable members is not sufficient to obtain a satisfactory sub-ensemble $E_{2}$ in terms of dispersion, it is possible to include members with an individual lower skill among the initial candidates, but in such a case all members would not be equiprobable anymore. We define ensemble $E_{4}$ by applying the selection method based on snow depth SS optimisation in the specific case where all the 7776 ESCROC members are candidates. The selection methods of the four sub-ensembles are summarised in Table 6.

\section{Results}

\subsection{Deterministic evaluation of the members and definition of the sub-ensemble of equiprobable members $E_{1}$}

Figure 7 shows the couple of scores $\left(\widehat{B}_{i}, \widehat{\mathrm{RMSE}}_{i}\right)$ of each ESCROC member and their confidence interval for the different evaluation variables. For each evaluation variable, the members cover a continuous range of bias and RMSE values. For snow surface properties (albedo, SST), this range is lower than the width of the confidence intervals of the scores of the best members. Very few members can be excluded from the ensemble on this criterion. However, for integrated variables (early, late and full-season snow depth, snow water equivalent, bulk density) and for the ground temperature, the range of the scores is larger than the confidence intervals of the best members. A significant number of members (30 to $80 \%$ depending on the variable) exhibit scores included in the confidence interval (i.e. the skills of these members are not significantly different from a statistical point of view). Only 575 members (about $7 \%$ ) exhibit, for all variables simultaneously, scores that are not significantly different from the best member. These members constitute the sub-ensemble $E_{1}$ as defined in Sect. 4.3.

\subsection{Probabilistic evaluation of the different sub-ensembles}

The sub-ensemble $E_{1}$ of $N_{1}=575$ optimal and equiprobable members is evaluated in terms of spread-skill and CRPS for the different evaluation variables. For all the variables, the magnitude of the spread ranges between 40 and $60 \%$ of the RMSE of the ensemble mean (Table 7, first column). This means that about half of the total uncertainty is unexplained by this sub-ensemble. As a result, the observation is frequently not included in the ensemble as illustrated by the overrepresentation of the extreme ranks in rank diagrams for all variables (Fig. 8, first column), especially for albedo consistently with the lower SS of this variable. This behaviour is also illustrated in the temporal plots: in Fig. 9, first column, the observed time series of snow depth is more than $10 \%$ of the time outside the $90 \%$ interval confidence of the ensemble (occurrences above the ensemble in 2003-2004 and 20102011 and conversely below the ensemble in 2006-2007 and 2007-2008). Several occurrences outside the ensemble can also be seen for bulk density and albedo during the season 2007-2008 (Fig. 10). Despite this underdispersion, the positive CRPSS (Table 8) demonstrate that sub-ensemble $E_{1}$ exhibits a better skill than the deterministic approach from a probabilistic point of view. The interest of the ensemble framework is also illustrated in Figs. 9 and 10 where observations are usually not superposed with the ensemble median but are found inside the ensemble spread with varying positions from one date to another. However, it is important to consider that the uncertainty in the evaluation data is not taken into account in this ensemble evaluation although it can impact the results. Thus, the imbalance between the first and last ranks frequencies in snow depth and SWE rank diagrams might suggest a positive bias of snow depth in $E_{1}$, but it is inconsistent with the negative bias of SWE and the lack of significant bias of BD. This behaviour can only be explained by the uncertainty in the reference data.

Among these 575 optimal members, the sub-ensembles $E_{2}$ and $E_{3}$ of $N_{2}=35$ members optimised in terms of spreadskill or CRPS of snow depth are selected following the 
Table 6. Summary of the four sub-ensembles.

\begin{tabular}{lllll}
\hline & $E_{1}$ & $E_{2}$ & $E_{3}$ & $E_{4}$ \\
\hline Restriction to the best members (deterministic scores) & yes & yes & yes & no \\
Restriction to $n^{\prime}=35$ members & no & yes & yes & yes \\
Optimisation criteria & & SS on SD & CRPS on SD & SS on SD
\end{tabular}
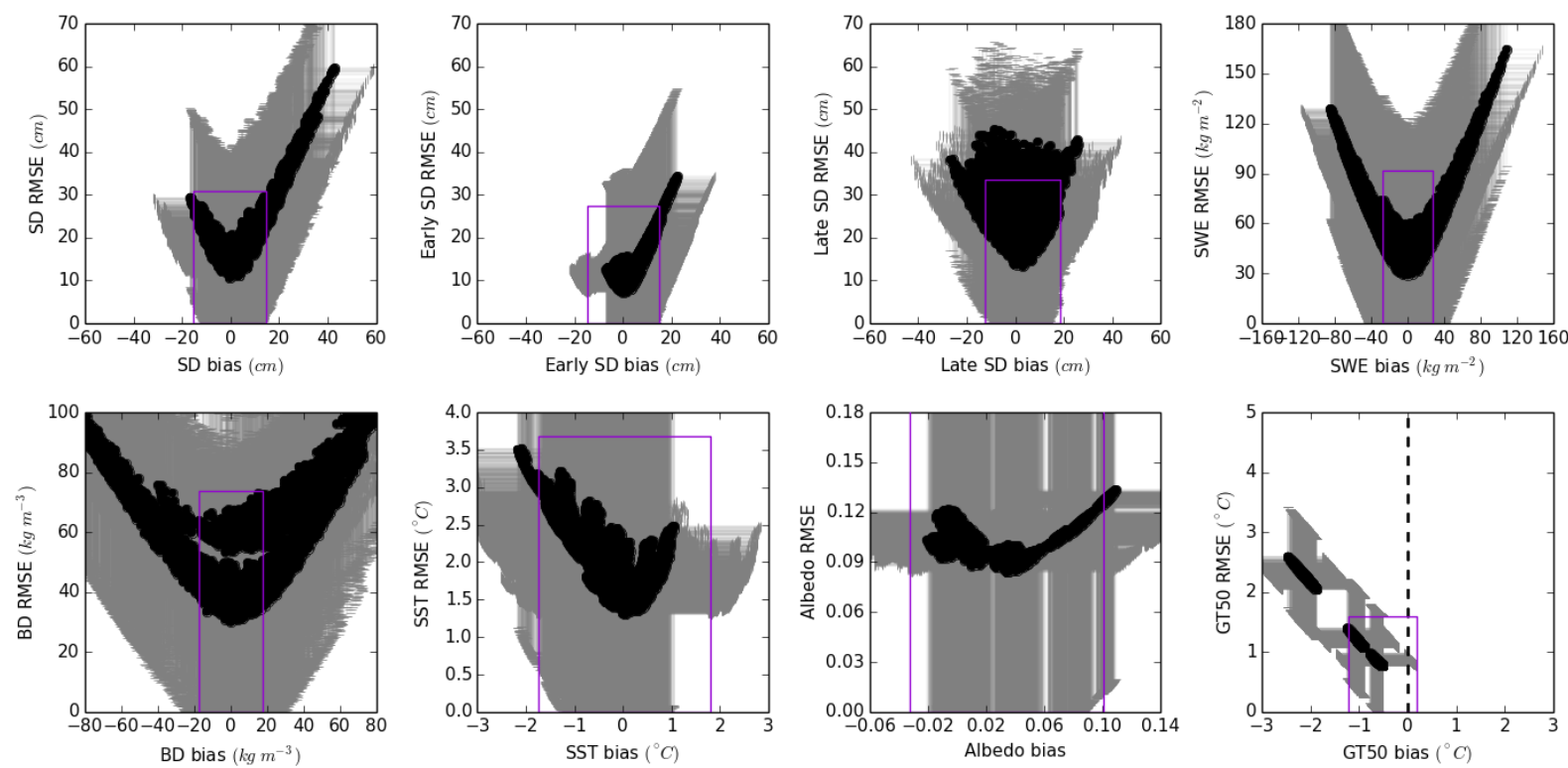

Figure 7. Scores of each member of the ESCROC ensemble for the different evaluation variables, 1993-2011. Black points represent the couple $\left(\widehat{B}_{i}, \widehat{\mathrm{RMSE}}_{i}\right)$ for each member. Grey crosses represent the $90 \%$ confidence interval of each score. The violet rectangle represents the $90 \%$ confidence interval associated to the best member according to its RMSE.

methodology of Sect. 4.3. The members are listed in Tables $\mathrm{A} 1$ and $\mathrm{A} 2$. The improved spread-skill of $E_{2}$, and even of $E_{3}$ (Table 7), illustrates that a much lower number of members are sufficient to represent model uncertainty if they are appropriately selected, and that including too many correlated members tends to reduce the dispersion. However, despite the SS optimisation, the sub-ensemble $E_{2}$ remains underdispersive for all variables. This is also the case for ensemble $E_{3}$, a fortiori. The U-shape of rank diagrams is only slightly smoothed (Fig. 8) and the simulated time series feature the same main issues between $E_{1}, E_{2}$ and $E_{3}$ (Figs. 9 and 10). It can also be noticed that the optimisation of either snow depth SS or snow depth CRPS degrades neither SS nor the CRPS for the other evaluation variables (Tables 7 and 8). The only exception is the CRPS of bulk density which is poorer for ensemble $E_{3}$ than for ensemble $E_{1}$.

To increase the dispersion, it is possible to relax the constraint of optimal skill in terms of bias and RMSE for some (or all) evaluation variables for the candidate members. Ensemble $E_{4}$ corresponds to the extreme case: we selected 35 members within all the 7776 ESCROC members by snow depth SS optimisation (list of members in Table A3). We can see that the spread-skill can be fully optimised for a chosen variable (perfect SS of snow depth in Table 7, much more flatter rank diagram in Fig. 8, and significant broadening of the $Q_{5}-Q_{95}$ interpercentile interval in Fig. 9, allowing the inclusion of the observed time series most of the time). However, it does not allow a simultaneous optimisation of the dispersion of the other variables: albedo and SST are still underdispersive, whereas SWE and BD become overdispersive (see also the bell-shaped rank diagrams). It can be noticed that although members with a lower individual skill are included, the CRPS are still enhanced for all variables compared to other sub-ensembles, even without any weighting of the less probable members. However, the significance of CRPS differences among the different sub-ensembles was not tested here.

\subsection{Model sensitivity to physical options}

It is useful to know if some physical options exhibit a significantly lower skill regardless of the options of the other processes. This is only the case for the default option of $10000 \mathrm{~J} \mathrm{~m}^{-2} \mathrm{~K}^{-1}$ for the soil surface heat capacity which leads to a systematic cold bias of ground temperature in autumn, as illustrated in Fig. 11, and in Decharme et al. (2016). 
Table 7. Spread-skill (dispersion/RMSE) of ESCROC sub-ensembles for the different evaluation variables, $1993-2011$.

\begin{tabular}{lrrrr}
\hline Variable & $E_{1}$ & $E_{2}$ & $E_{3}$ & $E_{4}$ \\
\hline SD $(\mathrm{cm})$ & $51 \%(8.5 / 16.5)$ & $65 \%(10.0 / 15.3)$ & $56 \%(8.0 / 14.3)$ & $100 \%(14.8 / 14.8)$ \\
SWE $\left(\mathrm{kg} \mathrm{m}^{-2}\right)$ & $51 \%(38.6 / 75.2)$ & $69 \%(48.6 / 70.2)$ & $57 \%(38.1 / 66.9)$ & $131 \%(82.9 / 63.2)$ \\
BD $\left(\mathrm{kg} \mathrm{m}^{-3}\right)$ & $60 \%(21.5 / 35.8)$ & $62 \%(22.0 / 35.5)$ & $62 \%(22.3 / 36.0)$ & $132 \%(45.7 / 34.7)$ \\
Albedo & $42 \%(0.034 / 0.081)$ & $46 \%(0.035 / 0.076)$ & $46 \%(0.035 / 0.076)$ & $52 \%(0.039 / 0.075)$ \\
SST (K) & $59 \%(1.03 / 1.74)$ & $61 \%(1.08 / 1.78)$ & $63 \%(0.98 / 1.54)$ & $70 \%(1.05 / 1.50)$ \\
\hline
\end{tabular}

Table 8. CRPS (CRPSS in parenthesis) of ESCROC sub-ensembles for the different evaluation variables, $1993-2011$.

\begin{tabular}{lrrrr}
\hline Variable & $E_{1}$ & $E_{2}$ & $E_{3}$ & $E_{4}$ \\
\hline SD $(\mathrm{cm})$ & $7.2(0.41)$ & $6.6(0.46)$ & $6.3(0.48)$ & $6.1(0.49)$ \\
SWE $\left(\mathrm{kg} \mathrm{m}^{-2}\right)$ & $40.2(0.30)$ & $36.8(0.36)$ & $36.9(0.36)$ & $32.8(0.43)$ \\
BD $\left(\mathrm{kg} \mathrm{m}^{-3}\right)$ & $19.4(0.26)$ & $19.5(0.25)$ & $22.3(0.15)$ & $18.5(0.29)$ \\
Albedo & $0.056(0.09)$ & $0.052(0.16)$ & $0.052(0.16)$ & $0.050(0.19)$ \\
SST (K) & $0.89(0.47)$ & $0.92(0.45)$ & $0.78(0.53)$ & $0.76(0.55)$ \\
\hline
\end{tabular}

As this option also exhibits a high sensitivity on integrated variables such as SD, SWE and BD, further investigations are necessary to better understand why this realistic value of surface heat capacity leads to a systematic bias at Col de Porte and if this issue also exists in other places in the Alps. For all the other options, their ability to provide optimal simulations depend on the choice of options for the other processes. Figure 12 represents the frequency of each physical option in the sub-ensemble $E_{1}$ of 575 optimal members. Regardless of the process, there is no option which is highly prevailing in this sub-ensemble population. Some options are less frequently represented than others (for instance options TA+ for solar radiation absorption, B02 for liquid water holding, T11 for snow compaction) but, when combined with specific options for the other processes, they are still able to exhibit realistic simulations for all evaluation variables. Regarding the solar radiation absorption representation, it must be noticed that the $\mathrm{TA}+$ and $\mathrm{B} 10$ do not exhibit any negative bias in albedo or snow depth evaluations (Fig. 13). Their lower frequencies in ensemble $E_{1}$ are mainly explained by the scores of SWE and late snow depth. The B60 option (blue points) could be associated with a positive bias of snow depth in the default Crocus version with a $10000 \mathrm{~J} \mathrm{~m}^{-2} \mathrm{~K}^{-1}$ surface heat capacity (down-facing triangle in Figs. 11 and 13), and the B10 or TA+ options could be preferred (left and right-facing triangles in Fig. 13). However, the opposite conclusion is obtained if the surface heat capacity option is changed: the positive bias of B60 disappears (right and up-facing triangles in Fig. 11) and a negative late snow depth bias appears in spring for B10 and TA+ (not shown). Numerous similar dependences of the skill of a given option on the choice of other processes were found, with interactions between waterholding capacity, compaction and snowfall density options (not shown) or between turbulent surface fluxes and solar radiation absorption options, among others.

To illustrate how the different options create dispersion in the optimal sub-ensembles, in Fig. 14 we compare the energy fluxes of two different members of the $E_{1}$ sub-ensemble of optimal members for one particular season (2003-2004). These two members were selected because they have different options for solar radiation absorption and turbulent fluxes (B60/M98 and TA+/RIL) but the same options for all other processes. The absorbed solar radiation is significantly higher in the members with the TA+/RIL options than in the member with the B60/M98 options, especially in February and March, whereas the turbulent heat fluxes are significantly lower in member with the TA+/RIL options than in member with the B60/M98 options. As a result, the temporal variations of the energy balance differs between the two members, with a higher positive balance for member B60/M98 during some windy and mild events in winter and conversely a higher positive balance during some sunny spring days for member TA+/RIL. Therefore, there is a slightly different chronology of melting in these members, although the final melt-out date difference is only 2 days. These differences are lower than model errors and lower than the uncertainty range of observations. This illustrates that very different contributions of energy fluxes to the energy equilibrium can result in a similar and optimal skill for all evaluated variables (both members are included in $E_{1}$ sub-ensemble). This equifinality also exists between the other physical processes and options, with some more complex interactions involving more than two processes. It explains (i) the difficulty of selecting a single-model and (ii) the dispersion obtained at a given point in time by several members seen as equivalent and optimal from a deterministic statistical evaluation. 

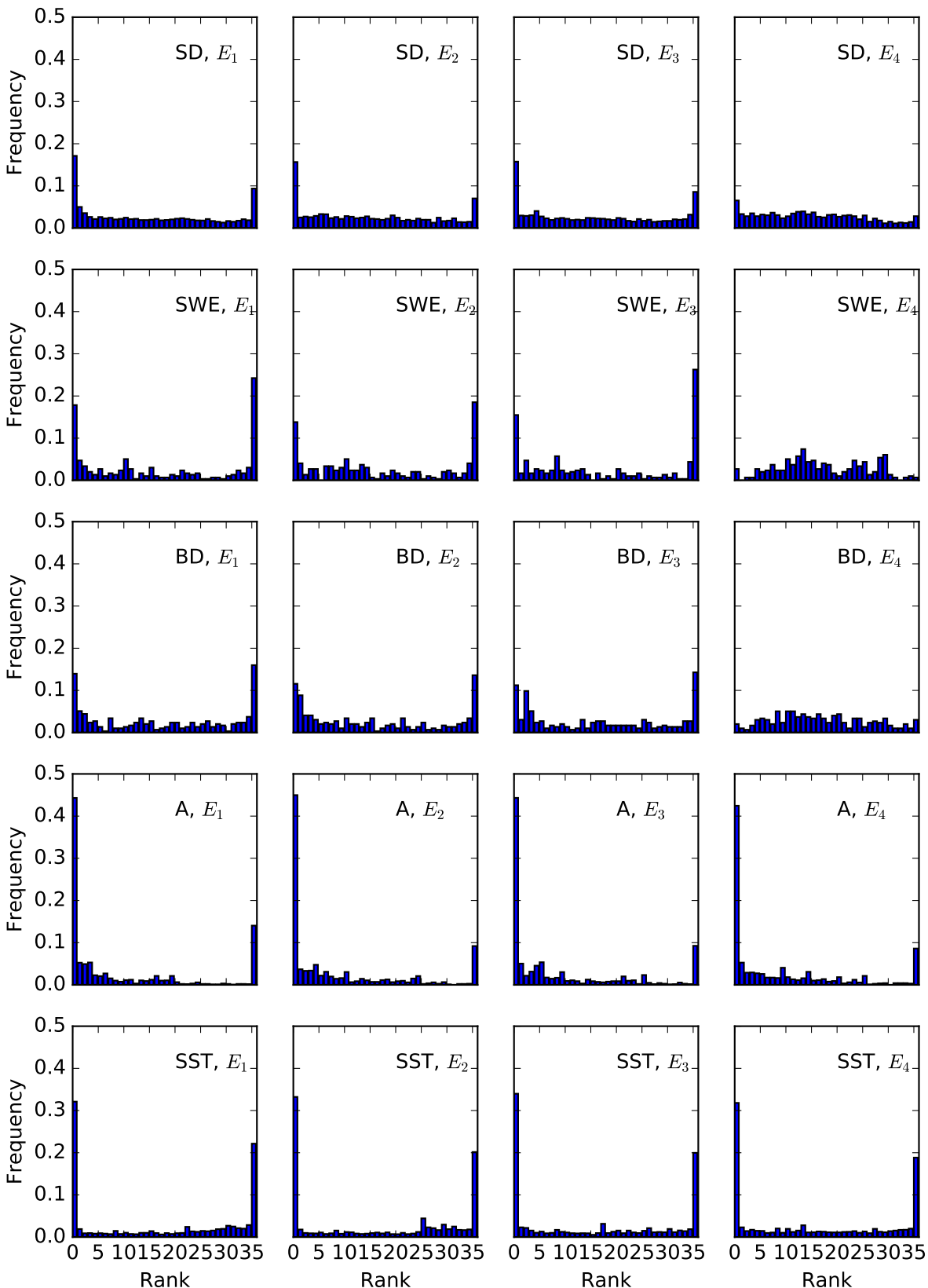

Figure 8. Rank diagrams for the different sub-ensembles $\left(E_{1}, E_{2}, E_{3}, E_{4}\right.$, by column) and evaluation variables (SD, SWE, BD, A, SST, by line), 1993-2011.

\section{Discussion}

The ability of ESCROC to explain a significant part of modelling errors at Col de Porte and its improved skill in terms of CRPS relative to deterministic modelling is very promising in that it contributes to the development of a full ensemble numerical system including ensemble meteorological forcing and ensemble data assimilation techniques in support of avalanche hazard forecasting. However, this work also has several limitations discussed in this section.

\subsection{Implications of forcing data uncertainty}

The assumption that meteorological input errors are low compared to model errors is the main limitation of our study because even at well-instrumented sites, recent studies illustrate that model outputs can be significantly affected by input errors, especially long-term biases (Raleigh et al., 2015) and by errors in longwave incident radiation and precipitation amount (Sauter and Obleitner, 2015). The quantification of the impact of meteorological uncertainties in snow 


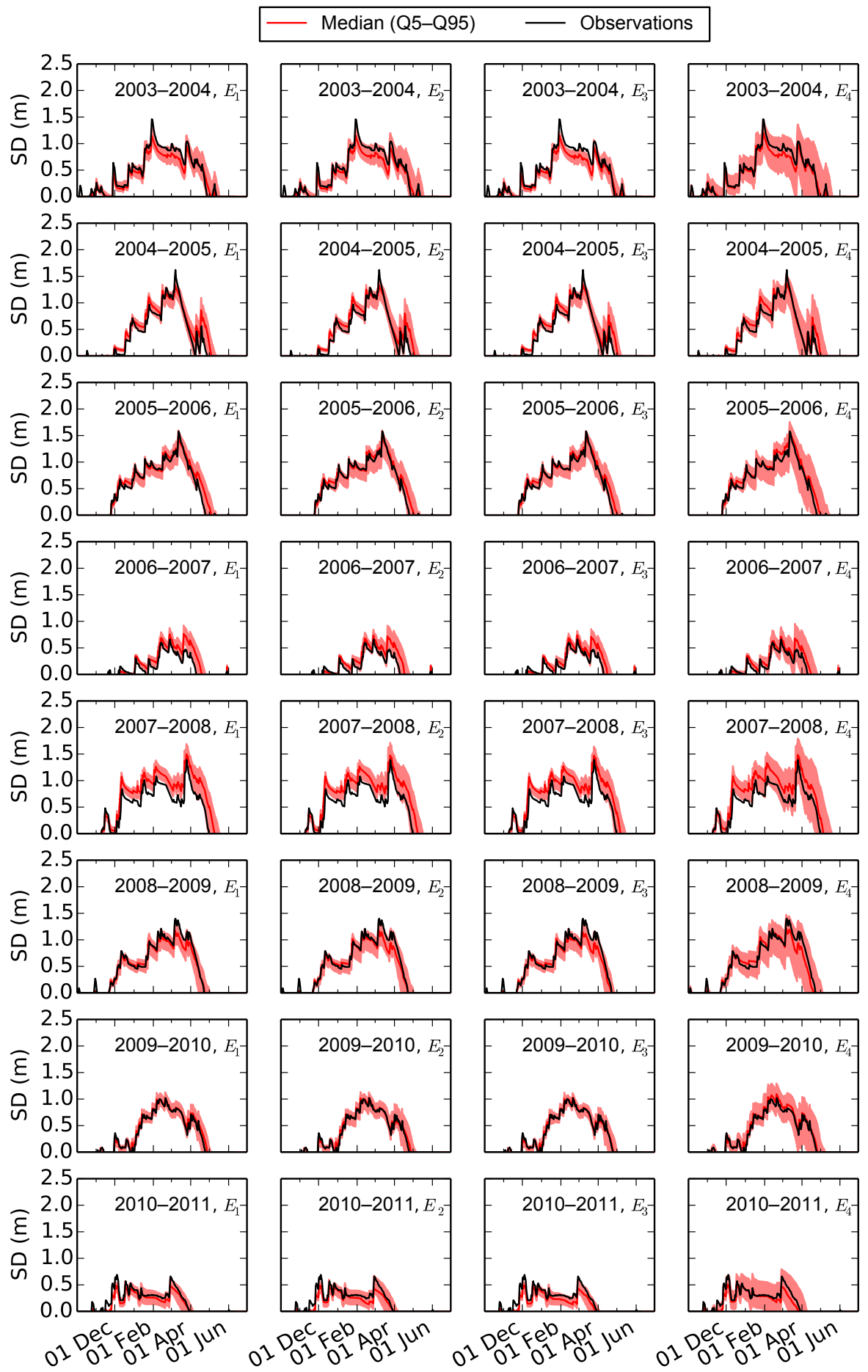

Figure 9. Simulated snow depth time series (median, 5th and 95th percentiles) for the different sub-ensembles $\left(E_{1}, E_{2}, E_{3}, E_{4}\right.$, by column), 2003-2011. Black line indicates observed snow depth.

modelling by Raleigh et al. (2015) is highly dependent on the choice of the error types (bias vs. random errors), and of the error distributions (form and parameters), whereas the accuracy specified by the manufacturers is difficult to interpret. Furthermore, additional errors can be encountered due to environment-specific issues. As a consequence, it is difficult to quantify an absolute contribution of forcing errors in the total uncertainty from manufacturers' information, and new investigations to document the meteorological uncertainty in experimental sites must be supported, as recently 

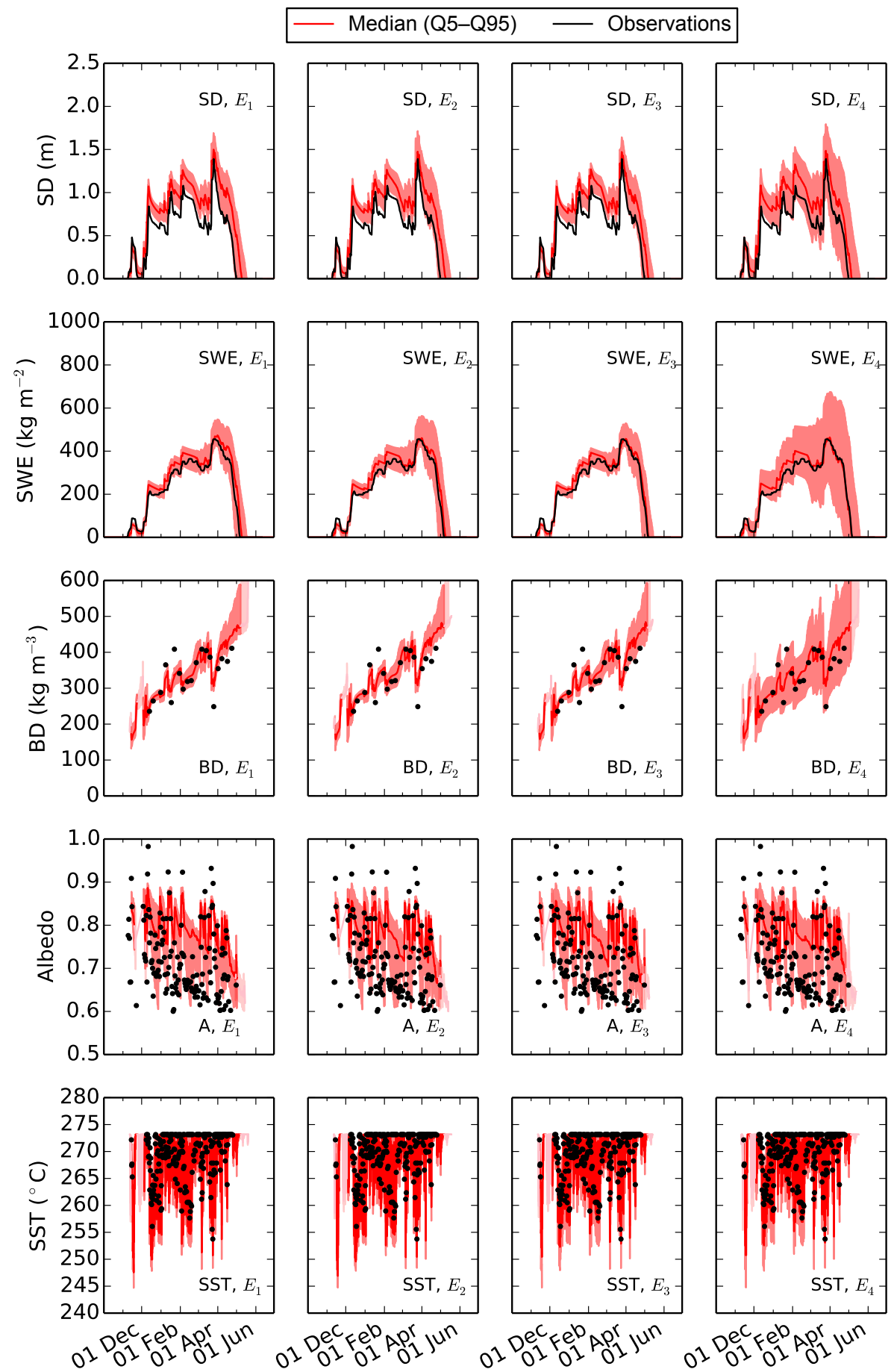

Figure 10. Simulated time series (median, 5th and 95th percentiles) of the different evaluation variables (by line), for the different subensembles ( $E_{1}, E_{2}, E_{3}, E_{4}$, by column), season 2007-2008. Black line or black points indicate observations.

done for precipitation amounts during the WMO Solid Precipitation Intercomparison Experiment (SPICE, e.g. Kochendorfer et al., 2017) which included the Col de Porte site. Nevertheless, Raleigh et al. (2015) calculated that the contribution of forcing errors specified from manufacturers may be as high as $40 \%$ of the total uncertainty for the most sensitive variables. This suggests that the underdispersion of the subensembles $E_{1}, E_{2}$ and $E_{3}$ of equiprobable members might be partly or totally explained by forcing uncertainty and not by an insufficient coverage of the uncertainty of physical pro- 

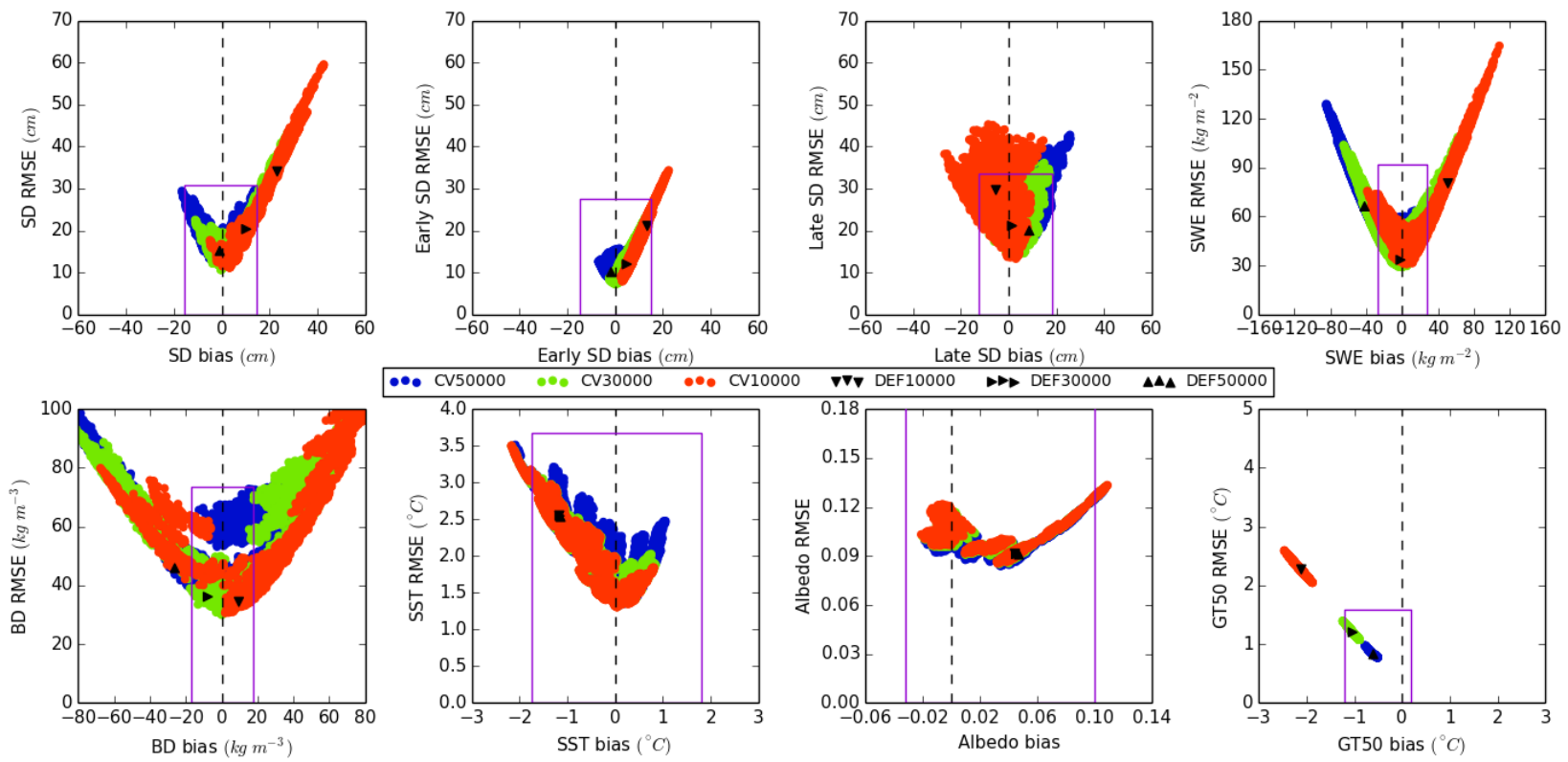

Figure 11. Same as Fig. 7 with different colours according to the option of surface heat capacity. The black triangles correspond to the default options of snow processes (blue cells in Fig. 2) and the three options of surface heat capacity.

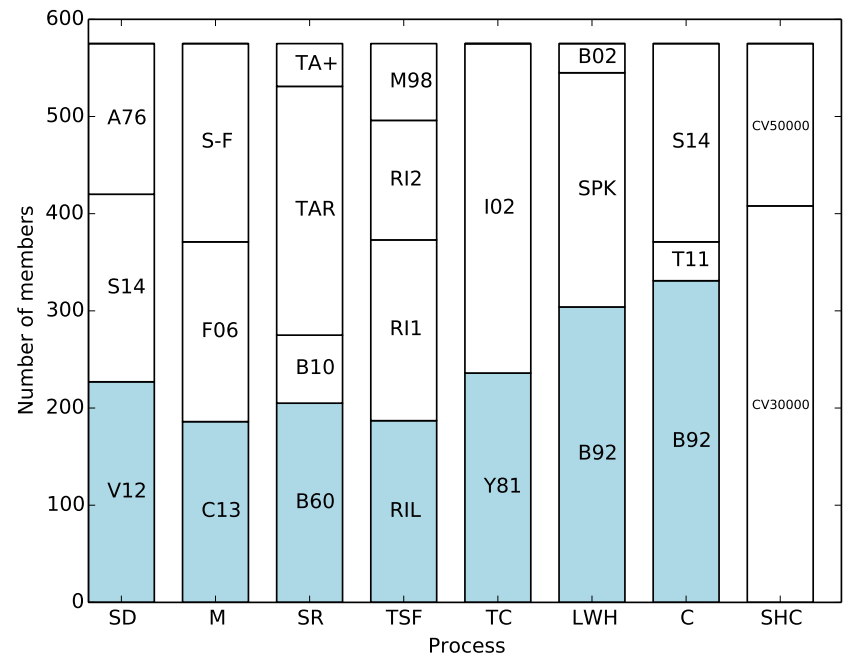

Figure 12. Number of occurrences of each physical option in the $E_{1}$ ensemble of 575 equiprobable members. Blue cells correspond to the default Crocus configuration.

cesses in ESCROC. This suggests that including lower skill members to optimise the dispersion could be an artificial compensation of not accounting for forcing errors in the simulations. Therefore, despite the slight enhancement of probabilistic scores, we recommend considering this method with caution. Furthermore, losing the equiprobability of members can be a disadvantage in practical applications.

\subsection{Implications of a single site application only}

The second limitation of this study is that all evaluations and selections of sub-ensembles were based on a single experimental site. Applications on increasingly large scales of the ESCROC system will be affected by much more significant errors in the meteorological forcing, preventing a large-scale calibration of multiphysics sub-ensembles. However, applications of the model in different environments, for instance at higher elevations or higher latitudes, might be affected by different error levels associated with the physical processes than at $\mathrm{Col}$ de Porte, and the spread of the proposed sub-ensembles might be insufficient to quantify this higher uncertainty. This is especially the case over areas affected by significant snowdrift. To reduce this issue, the next important step will be to evaluate ESCROC in contrasted environments using other well-instrumented sites around the world often used for snow models evaluation, e.g. Sodankylä, Finland (Essery et al., 2016) or Weissfluhjoch, Switzerland (WSL, 2015). Forcing and evaluation data gathered by the ESM-SnowMIP initiative (http://www.climate-cryosphere. org/activities/targeted/esm-snowmip) will be used for this purpose.

\subsection{Limitations of scores and selection methods}

Our results illustrate that a realistic number of members can be sufficient to explain the uncertainty range. Nevertheless, the selection of optimal members presented here is affected by an uncertain characterisation of evaluation data errors (Sect. 4). The selection is not unique as only a limited num- 

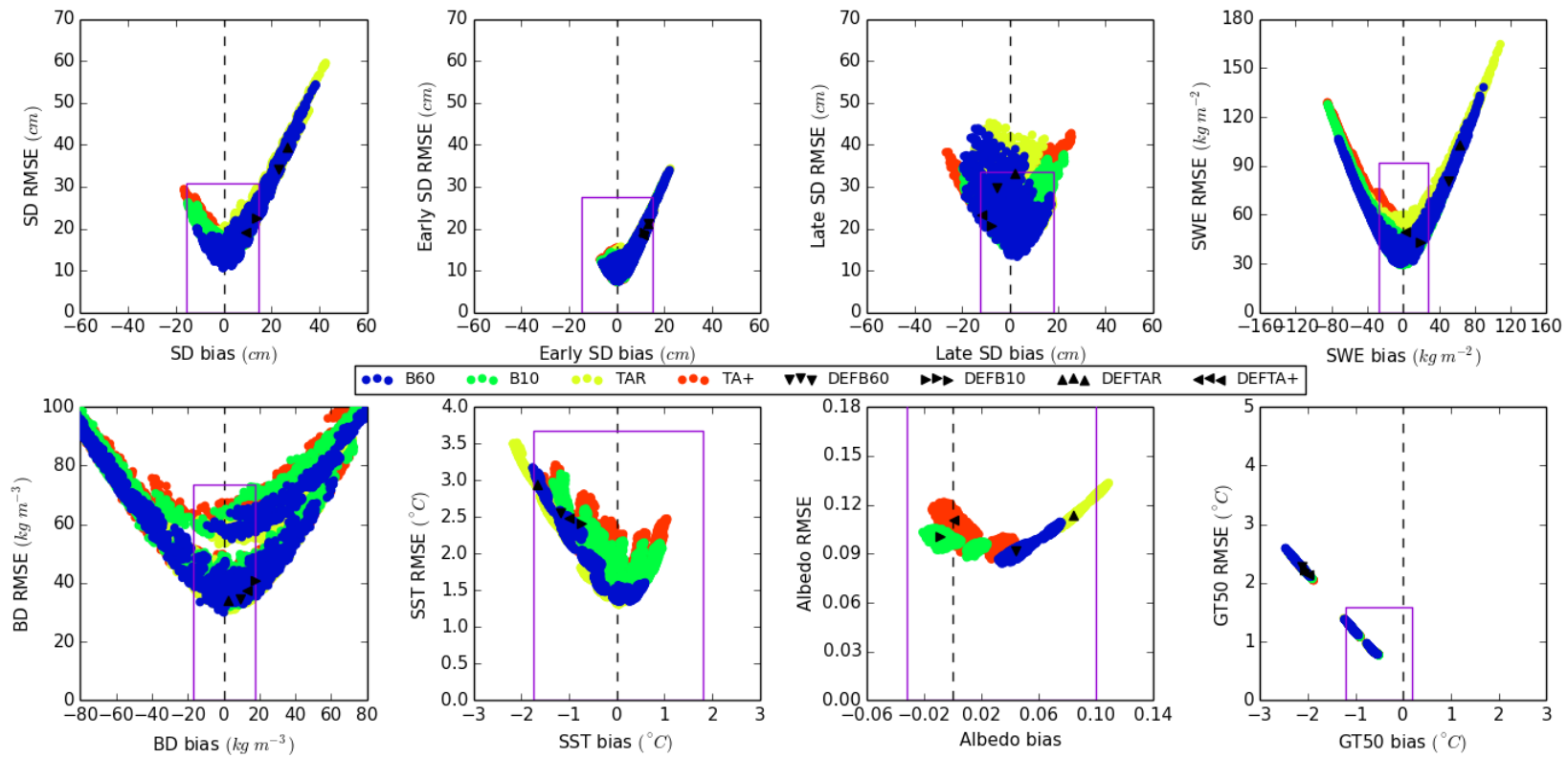

Figure 13. Same as Fig. 7 with different colours according to the option of solar radiation absorption. As in Fig. 11, the black triangles correspond to the default options of snow processes (blue cells in Fig. 2) and the three options of solar radiation absorption.

ber of possible combinations were randomly tested and it can be objective dependent. This paper presents a framework which may be adapted for a specific application. For instance, ensemble assimilation of remotely sensed spectral visible reflectances as in Charrois et al. (2016) would probably require selecting a sub-ensemble by albedo spread-skill optimisation. Because the uncertainty of albedo measurements is high, it would probably benefit from a better modelling of observations errors in both deterministic and probabilistic scores. In a more general context of a full ensemble system of snowpack modelling with various applications, the selection of members might be improved by defining multiobjective probabilistic criteria combining several evaluation variables or even several evaluation sites. Recent investigations on that topic for the purpose of ensemble meteorological forecasting proposed generalisations of the classical univariate probabilistic tools (Gneiting et al., 2008; Scheuerer and Hamill, 2015; Thorarinsdottir et al., 2016) which could be tested in ensemble snow modelling. Special care should be taken in the future to deal with the covariance of errors among the different evaluation variables. Increasing the number of dimensions in the evaluation framework by incorporating new sites or new variables such as vertical profiles of temperature, density or microstructure properties, is also likely to result in an empty ensemble in the first selection of members with an optimal deterministic skill over all these variables. This would also require defining multivariate deterministic evaluation criteria as in Essery et al. (2013).

\subsection{Lessons for numerical snowpack modelling}

Our results also illustrate the fact that all evaluations of numerical snow modelling are highly impacted by the choice of evaluation variables, the uncertainty of evaluation data and the physical options chosen for all physical processes even if they are beyond the scope of a particular study. As a result, a sensitivity test to choose the best physical representation of a given physical process can be misleading if the sensitivity to other processes is not explored or if the chosen evaluated variables do not constrain the model sufficiently. These conclusions are fully in accordance with Essery et al. (2013) and should be considered for the evaluation of any parameterisation of a physical-based snow model. It was unfortunately rarely done in past evaluations of most snow models.

ESCROC could be seen as a potential tool to quantify the relative contribution of each physical process to the overall uncertainty in snowpack modelling, e.g. using variance analysis methods as in Sauter and Obleitner (2015). This would provide a useful characterisation of the system itself but without any guarantee that these contributions are fully representative of snowpack modelling in a general context. Indeed, the results would be totally dependent on the choices made to define the different options. The latter may not accurately quantify the uncertainty process by process and it would be especially challenging to objectively verify the dispersion for each process.

Our results also illustrate the fact that looking for a perfect deterministic snowpack model might never be sufficient and that finding ways to deal with model errors may be as promising as improving the physics description. In 

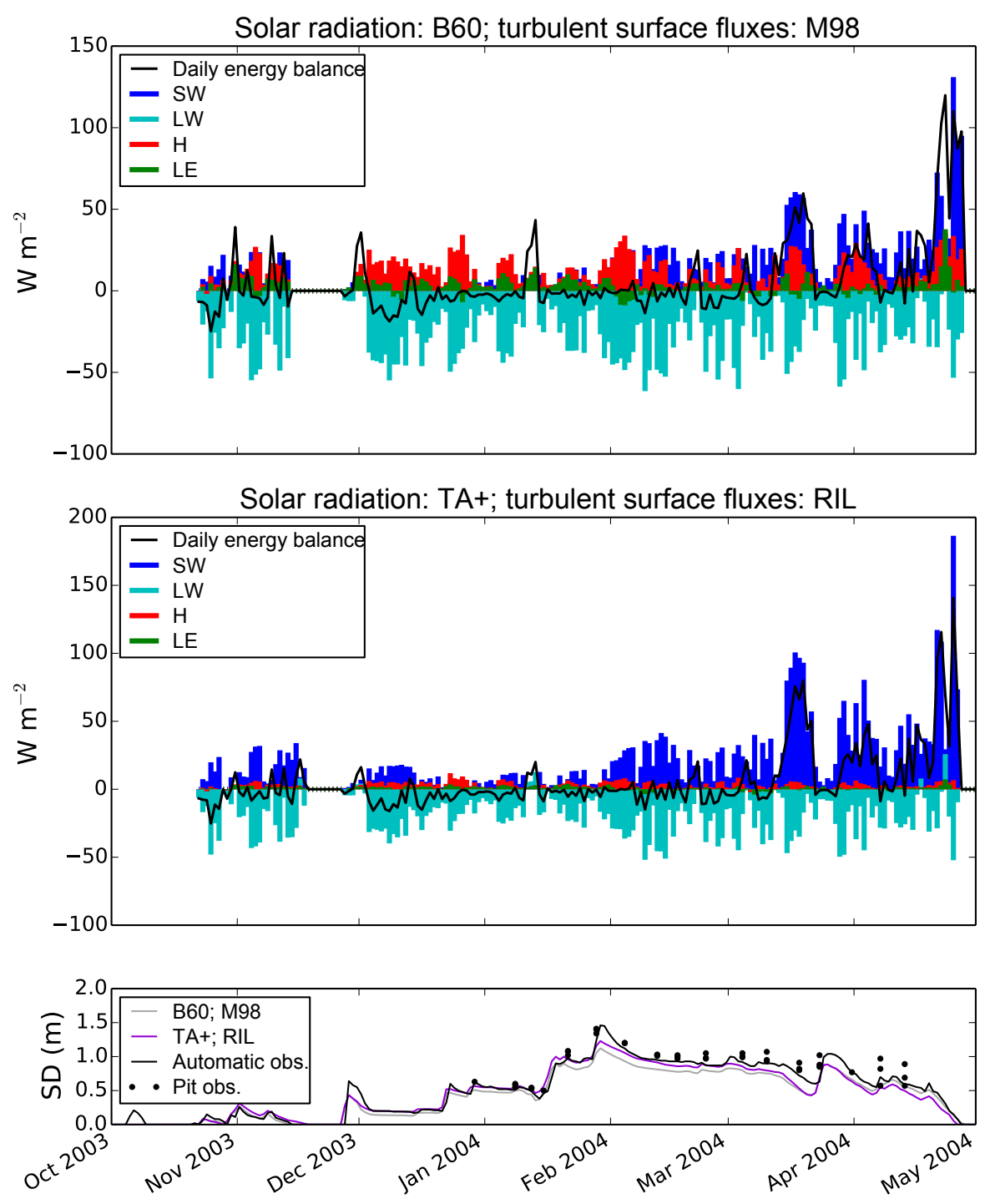

Figure 14. Daily simulated energy fluxes (shortwave net radiation SW, longwave net radiation LW, sensible heat flux $H$ and latent heat flux LE) and total energy balance for two members of ensemble $E_{1}$ differing in their options of solar radiation absorption and turbulent surface fluxes (B60/M98 and TA+/RIL). Both members share the same options for the other processes: I02 thermal conductivity, surface heat capacity of $3 \times 10^{5} \mathrm{~J} \mathrm{~m}^{-2} \mathrm{~K}^{-1}$, and default options for the other processes. Bottom plot represents the simulated total snow depth of both members and observations from the automatic ultrasound sensor and from the three manual weekly snow pits. Season $2003-2004$.

the Crocus snowpack model, recent attempts to introduce more sophisticated physics (e.g. metamorphism by Carmagnola et al., 2014, or implementation of the TARTES optical scheme) did not necessary lead to a significant overall skill improvement, as shown here. However, efforts to improve the physics is also in some cases expected to improve the details of the simulated snowpack vertical structure. For instance, solving Richards equations for the liquid water percolation would allow simulating the ponding of liquid water on capillary barriers and crusts with expected positive impacts on the detailed snow stratigraphy (Wever et al., 2015). Including water vapour transfers in snow modelling might also correct the unrealistic density profiles usually obtained in polar re- gions where this process is significant (Domine et al., 2013). Nevertheless, the modelling of these complex processes are bound to introduce new uncertainties. Therefore, progress in snow physics understanding and in ensemble modelling techniques have to be complementary to generally improve the reliability and the usefulness of snow simulations in various applications (e.g. avalanche hazard forecasting, hydrology, glaciers mass balance, climate change impact studies). 


\section{Conclusions}

Numerical snow modelling is affected by various sources of errors which reduce its current reliability and utility in operational applications. Following the progress achieved in meteorology and hydrology, we suggest that three directions in snowpack modelling should be explored at the same time:

- improving the quality of the meteorological forcing and the modelling of the physical processes,

- predicting the uncertainties of the simulations using ensemble frameworks covering all the errors sources,

- assimilating remotely sensed or conventional snowpack observations to reduce the errors.

While the first point has been the central topic of investigations in the last 30 years, the other two are only emergent. They are also highly linked as the concept of data assimilation relies on an accurate quantification of modelling errors. In this paper, we contribute to both these innovative topics by proposing a new multiphysics ensemble system of snowpack modelling, ESCROC, based on the implementation in the SURFEX/ISBA/Crocus snowpack model of various options for eight key processes in the evolution of midlatitude snowpacks. This system was evaluated with both deterministic and probabilistic tools at the $\mathrm{Col}$ de Porte well-instrumented site to reduce meteorological forcing errors as much as possible.

The deterministic skill of the ESCROC members cover a wider range than the uncertainty range of evaluation data for snow depth, snow water equivalent, bulk density and ground temperature. It is not the case for albedo and snow surface temperature which have measurements that feature higher uncertainty. The results confirm several conclusions of Essery et al. (2013), including the high equifinality between various processes in snow modelling which cannot be eliminated with standard evaluation methods and should therefore be carefully considered in future work intending to improve snow physics.
To define an ensemble of equiprobable members suited to ensemble forecasting and ensemble assimilation applications, a sub-ensemble of best members for all evaluation variables was selected and a methodological framework to select a reduced number of members was presented. Thus, sub-ensembles of only 35 members are able to explain between 50 and $70 \%$ of the total simulation errors. They have a significantly better predictive power than the classical deterministic approach. It is possible to optimise the ensemble spread-skill by including members with a lower deterministic skill, but we do not recommend it because it could be an artificial compensation of not accounting for forcing errors and because it would make the practical use of the ensemble in operational applications more complicated. Several perspectives are listed for future works, including the extension of evaluations to a multi-site and multivariate analysis. Another important perspective will be to test the combination of this multiphysics system with ensemble meteorological forecasts suited to snowpack simulations (Vernay et al., 2015). The development of ensemble meteorological analyses instead of current deterministic systems (Durand et al., 1993) will also be a challenge, especially in the context of the increased resolution of NWP models (Vionnet et al., 2016). The most appropriate way to propagate and reduce both uncertainties will also have to be investigated when this full ensemble system is combined with an ensemble data assimilation algorithm. Last but not least, the development of synthesis diagnostics of ensemble simulations is essential to assist the avalanche hazard forecasters in taking advantage of an increasing amount of available data.

Code and data availability. ESCROC is developed inside the open source SURFEX project (http://www.umr-cnrm.fr/surfex). While it is not implemented in an official SURFEX release, the code can be downloaded from the specific branch of the svn repository maintained by Centre d'Études de la Neige. The full procedure and documentation can be found at https://opensource.cnrm-game-meteo. fr/projects/snowtools/wiki/Procedure_for_new_users. For reproductibility of results, the version used in this work is tagged as http://svn.cnrm-game-meteo.fr/projets/surfex/tags/ESCROC-1.0.

The CDP data set is placed on the PANGAEA repository (doi:10.1594/PANGAEA.774249) as well as on the public ftp server ftp://ftp-cnrm.meteo.fr/pub-cencdp. 
Appendix A: List of members of sub-ensembles $E_{2}, E_{3}$ and $E_{4}$

Table A1. List of equiprobable members of sub-ensemble $E_{2}$ (optimised in terms of snow depth dispersion).

\begin{tabular}{|c|c|c|c|c|c|c|c|c|}
\hline & SD & M & SR & TSF & $\mathrm{TC}$ & LWH & $\mathrm{C}$ & SHC \\
\hline 1 & V12 & C13 & B60 & RI1 & Y81 & SPK & B92 & CV30000 \\
\hline 2 & V12 & C13 & B60 & RI1 & I02 & B92 & S14 & CV30000 \\
\hline 3 & V12 & $\mathrm{C} 13$ & B60 & RI2 & Y81 & B92 & S14 & CV30000 \\
\hline 4 & V12 & $\mathrm{C} 13$ & B10 & RIL & Y81 & B92 & B92 & CV30000 \\
\hline 5 & V12 & C13 & TAR & RI1 & I02 & SPK & T11 & CV50000 \\
\hline 6 & V12 & C13 & TAR & RI2 & I02 & SPK & S14 & CV50000 \\
\hline 7 & V12 & $\mathrm{C} 13$ & $\mathrm{TA}+$ & RI1 & I02 & SPK & B92 & CV30000 \\
\hline 8 & V12 & F06 & B60 & RIL & Y81 & B92 & S14 & CV30000 \\
\hline 9 & V12 & F06 & B60 & RIL & Y81 & SPK & S14 & CV50000 \\
\hline 10 & V12 & F06 & TAR & RIL & I02 & B92 & T11 & CV50000 \\
\hline 11 & V12 & S-F & B60 & RI1 & I02 & B92 & S14 & CV30000 \\
\hline 12 & V12 & S-F & B10 & RI2 & I02 & SPK & B92 & CV30000 \\
\hline 13 & V12 & S-F & TAR & RIL & Y81 & SPK & S14 & CV50000 \\
\hline 14 & V12 & S-F & TAR & RIL & Y81 & SPK & S14 & CV30000 \\
\hline 15 & V12 & S-F & TAR & M98 & Y81 & SPK & B92 & CV30000 \\
\hline 16 & V12 & S-F & $\mathrm{TA}+$ & RIL & I02 & SPK & B92 & CV30000 \\
\hline 17 & S14 & C13 & B60 & M98 & Y81 & B92 & S14 & CV30000 \\
\hline 18 & S14 & C13 & $\mathrm{TA}+$ & RI1 & I02 & B92 & B92 & CV30000 \\
\hline 19 & S14 & F06 & B60 & RIL & Y81 & B92 & S14 & CV50000 \\
\hline 20 & S14 & F06 & B60 & M98 & I02 & B92 & B92 & CV30000 \\
\hline 21 & S14 & F06 & B60 & M98 & I02 & SPK & B92 & CV30000 \\
\hline 22 & S14 & F06 & TAR & RI1 & Y81 & SPK & B92 & CV30000 \\
\hline 23 & S14 & F06 & $\mathrm{TA}+$ & RIL & I02 & SPK & B92 & CV30000 \\
\hline 24 & S14 & F06 & $\mathrm{TA}+$ & RI1 & I02 & SPK & B92 & CV30000 \\
\hline 25 & S14 & S-F & B60 & RIL & I02 & B92 & B92 & CV50000 \\
\hline 26 & S14 & S-F & B60 & RIL & I02 & SPK & S14 & CV50000 \\
\hline 27 & S14 & S-F & B60 & RI1 & I02 & SPK & B92 & CV30000 \\
\hline 28 & S14 & S-F & TAR & RIL & I02 & SPK & S14 & CV50000 \\
\hline 29 & A76 & F06 & B60 & M98 & I02 & B02 & S14 & CV30000 \\
\hline 30 & A76 & F06 & TAR & M98 & I02 & SPK & B92 & CV30000 \\
\hline 31 & A76 & F06 & $\mathrm{TA}+$ & RIL & I02 & B92 & B92 & CV30000 \\
\hline 32 & A76 & S-F & B10 & RIL & Y81 & B92 & B92 & CV30000 \\
\hline 33 & A76 & S-F & B10 & RI2 & I02 & B92 & B92 & CV30000 \\
\hline 34 & A76 & S-F & TAR & RIL & Y81 & SPK & S14 & CV50000 \\
\hline 35 & A76 & S-F & TAR & RI1 & Y81 & SPK & B92 & CV30000 \\
\hline
\end{tabular}

Table A2. List of equiprobable members of sub-ensemble $E_{3}$ (optimised in terms of snow depth CRPS).

\begin{tabular}{|c|c|c|c|c|c|c|c|c|}
\hline & $\mathrm{SD}$ & M & SR & TSF & $\mathrm{TC}$ & LWH & $\mathrm{C}$ & SHC \\
\hline 1 & V12 & $\mathrm{C} 13$ & B60 & RIL & I02 & B92 & $\mathrm{T} 11$ & CV50000 \\
\hline 2 & V12 & $\mathrm{C} 13$ & B60 & RI2 & Y81 & B92 & B92 & CV30000 \\
\hline 3 & V12 & $\mathrm{C} 13$ & B60 & RI2 & I02 & SPK & B92 & CV30000 \\
\hline 4 & V12 & $\mathrm{C} 13$ & B60 & M98 & I02 & SPK & B92 & CV30000 \\
\hline 5 & V12 & $\mathrm{C} 13$ & B10 & RIL & Y81 & SPK & B92 & CV30000 \\
\hline 6 & V12 & $\mathrm{C} 13$ & B10 & RI1 & I02 & B92 & B92 & CV30000 \\
\hline 7 & V12 & $\mathrm{C} 13$ & TAR & RI2 & Y81 & B92 & S14 & CV30000 \\
\hline 8 & V12 & F06 & B60 & RI2 & Y81 & SPK & B92 & CV30000 \\
\hline 9 & V12 & F06 & TAR & RI1 & I02 & SPK & $\mathrm{T} 11$ & CV50000 \\
\hline 10 & V12 & S-F & B60 & RI1 & I02 & SPK & B92 & CV50000 \\
\hline 11 & V12 & S-F & B10 & RIL & Y81 & B92 & B92 & CV30000 \\
\hline 12 & V12 & S-F & TAR & M98 & Y81 & SPK & S14 & CV30000 \\
\hline 13 & V12 & S-F & $\mathrm{TA}+$ & RI1 & I02 & SPK & B92 & CV30000 \\
\hline 14 & S14 & $\mathrm{C} 13$ & B60 & RIL & I02 & SPK & B92 & CV50000 \\
\hline 15 & S14 & $\mathrm{C} 13$ & TAR & RI2 & I02 & SPK & S14 & CV50000 \\
\hline 16 & S14 & $\mathrm{C} 13$ & TAR & M98 & Y81 & B92 & S14 & CV30000 \\
\hline 17 & $\mathrm{~S} 14$ & F06 & B60 & M98 & Y81 & B92 & S14 & CV30000 \\
\hline 18 & S14 & F06 & TAR & RIL & Y81 & SPK & S14 & CV50000 \\
\hline 19 & S14 & F06 & $\mathrm{TA}+$ & RI1 & I02 & SPK & B92 & CV 30000 \\
\hline 20 & S14 & S-F & B60 & RIL & Y81 & B92 & S14 & CV30000 \\
\hline 21 & S14 & S-F & B60 & RI1 & I02 & B92 & S14 & CV50000 \\
\hline 22 & S14 & S-F & B60 & M98 & I02 & B92 & B92 & CV30000 \\
\hline 23 & S14 & S-F & $\mathrm{B} 60$ & M98 & I02 & B92 & S14 & CV30000 \\
\hline 24 & S14 & S-F & TAR & RI2 & I02 & B92 & B92 & CV30000 \\
\hline 25 & S14 & S-F & TAR & M98 & I02 & SPK & B92 & CV30000 \\
\hline 26 & S14 & S-F & $\mathrm{TA}+$ & RI1 & I02 & SPK & B92 & CV30000 \\
\hline 27 & A76 & $\mathrm{C} 13$ & B60 & RI2 & I02 & B92 & B92 & CV30000 \\
\hline 28 & A76 & $\mathrm{C} 13$ & $\mathrm{~B} 60$ & M98 & I02 & B02 & S14 & CV30000 \\
\hline 29 & A76 & $\mathrm{C} 13$ & B10 & $\mathrm{RI} 2$ & I02 & B92 & B92 & CV30000 \\
\hline 30 & A76 & $\mathrm{C} 13$ & TAR & RI1 & Y81 & B92 & S14 & CV50000 \\
\hline 31 & A76 & F06 & B60 & RI1 & Y81 & B92 & B92 & CV30000 \\
\hline 32 & A76 & F06 & $\mathrm{B} 60$ & M98 & Y81 & B02 & S14 & CV 30000 \\
\hline 33 & A76 & F06 & B10 & RIL & Y81 & B92 & B92 & CV30000 \\
\hline 34 & A76 & F06 & TAR & RI2 & I02 & B92 & B92 & CV30000 \\
\hline 35 & A76 & S-F & $\mathrm{TA}+$ & RI1 & I02 & B92 & B92 & CV30000 \\
\hline
\end{tabular}


Table A3. List of non-equiprobable members of sub-ensemble $E_{4}$ (optimised in terms of snow depth dispersion).

\begin{tabular}{|c|c|c|c|c|c|c|c|c|}
\hline & SD & M & SR & TSF & $\mathrm{TC}$ & LWH & $\mathrm{C}$ & SHC \\
\hline 1 & V12 & C13 & B60 & RI2 & I02 & SPK & B92 & CV50000 \\
\hline 2 & V12 & C13 & B10 & M98 & Y81 & B02 & B92 & CV30000 \\
\hline 3 & V12 & C13 & TAR & RIL & Y81 & B92 & B92 & CV50000 \\
\hline 4 & V12 & C13 & $\mathrm{TA}+$ & RI1 & Y81 & B92 & B92 & CV50000 \\
\hline 5 & V12 & C13 & $\mathrm{TA}+$ & RI2 & I02 & SPK & T11 & CV50000 \\
\hline 6 & V12 & F06 & B60 & RIL & I02 & SPK & $\mathrm{T} 11$ & CV10000 \\
\hline 7 & V12 & F06 & B60 & RI2 & I02 & B92 & S14 & CV50000 \\
\hline 8 & V12 & F06 & TAR & RIL & I02 & SPK & S14 & CV50000 \\
\hline 9 & V12 & S-F & B60 & RI2 & Y81 & B92 & S14 & CV50000 \\
\hline 10 & V12 & S-F & B60 & RI2 & I02 & B02 & S14 & CV50000 \\
\hline 11 & V12 & S-F & B10 & RI1 & I02 & SPK & B92 & CV30000 \\
\hline 12 & V12 & S-F & B10 & M98 & I02 & B02 & S14 & CV10000 \\
\hline 13 & V12 & S-F & TAR & M98 & Y81 & B92 & B92 & CV10000 \\
\hline 14 & S14 & $\mathrm{C} 13$ & B60 & RIL & I02 & SPK & S14 & CV30000 \\
\hline 15 & S14 & C13 & B10 & RIL & Y81 & B92 & B92 & CV10000 \\
\hline 16 & S14 & $\mathrm{C} 13$ & TAR & RI1 & I02 & B92 & B92 & CV30000 \\
\hline 17 & S14 & F06 & B60 & RI2 & I02 & SPK & S14 & CV50000 \\
\hline 18 & S14 & F06 & B10 & RIL & I02 & B02 & S14 & CV30000 \\
\hline 19 & S14 & F06 & B10 & RI1 & I02 & B92 & B92 & CV30000 \\
\hline 20 & S14 & F06 & TAR & RI2 & I02 & SPK & B92 & CV30000 \\
\hline 21 & S14 & S-F & B60 & RI2 & Y81 & B92 & T11 & CV30000 \\
\hline 22 & S14 & S-F & B60 & RI2 & I02 & SPK & S14 & CV30000 \\
\hline 23 & S14 & S-F & B10 & M98 & Y81 & B92 & B92 & CV10000 \\
\hline 24 & S14 & S-F & TAR & RI2 & I02 & B02 & B92 & CV30000 \\
\hline 25 & S14 & S-F & TAR & M98 & Y81 & B92 & S14 & CV50000 \\
\hline 26 & A76 & C13 & TAR & RI2 & Y81 & SPK & S14 & CV10000 \\
\hline 27 & A76 & $\mathrm{C} 13$ & TAR & RI2 & Y81 & B02 & S14 & CV50000 \\
\hline 28 & A76 & C13 & $\mathrm{TA}+$ & RIL & I02 & SPK & T11 & CV10000 \\
\hline 29 & A76 & F06 & B60 & M98 & Y81 & B02 & S14 & CV10000 \\
\hline 30 & A76 & F06 & TAR & RI2 & I02 & B92 & S14 & CV30000 \\
\hline 31 & A76 & F06 & $\mathrm{TA}+$ & M98 & I02 & B92 & B92 & CV30000 \\
\hline 32 & A76 & S-F & B60 & RI1 & Y81 & SPK & B92 & CV10000 \\
\hline 33 & A76 & S-F & B10 & RIL & Y81 & B92 & B92 & CV30000 \\
\hline 34 & A76 & S-F & B10 & M98 & I02 & B02 & B92 & CV30000 \\
\hline 35 & A76 & S-F & $\mathrm{TA}+$ & RI2 & I02 & SPK & B92 & CV10000 \\
\hline
\end{tabular}


Competing interests. The authors declare that they have no conflict of interest.

Acknowledgements. The authors would like to thank all the staff of Centre d'Études de la Neige involved in data acquisition at Col de Porte since 1993, especially J. M. Panel, B. Lesaffre, D. Poncet, E. Le Gac, E. Pougatch, Y. Daniélou, P. David and M. Sudul and EDF-DTG which operate automated SWE measurements. CNRM/CEN is part of LabEx OSUG@2020 (ANR10 LABX56). The CDP observatory belongs to OSUG/CENACLAM, the SOERE CRYOBSCLIM, the GCW CryoNet network and INARCH. The authors also thank Richard Essery and the second anonymous reviewer for their careful revision, which helped improve the manuscript.

Edited by: C. Haas

Reviewed by: R. L. H. Essery and one anonymous referee

\section{References}

Anderson, E. A.: A point energy and mass balance model of a snow cover, Tech. rep., Office of Hydrology - National Weather Service, 1976.

Bartelt, P. and Lehning, M.: A physical SNOWPACK model for the Swiss avalanche warning: Part I: numerical model, Cold Reg. Sci. Technol., 35, 123-145, 2002.

Bellaire, S. and Jamieson, B.: Forecasting the formation of critical snow layers using a coupled snow cover and weather model, Cold. Reg. Sci. Technol., 94, 37-44, doi:10.1016/j.coldregions.2013.06.007, 2013.

Boone, A.: Description du schema de neige ISBA-ES (Explicit Snow), Tech. rep., Note de Centre, Meteo-France/CNRM, 59 pp., 2002.

Boone, A. and Etchevers, P.: An intercomparison of three snow schemes of varying complexity coupled to the same land-surface model: Local scale evaluation at an Alpine site, J. Hydrometeorol., 2, 374-394, doi:10.1175/15257541(2001)002<0374:AIOTSS>2.0.CO;2, 2001.

Brun, E., Martin, E., Simon, V., Gendre, C., and Coléou, C.: An energy and mass model of snow cover suitable for operational avalanche forecasting, J. Glaciol., 35, 333-342, 1989.

Brun, E., David, P., Sudul, M., and Brunot, G.: A numerical model to simulate snow-cover stratigraphy for operational avalanche forecasting, J. Glaciol., 38, 13-22, 1992.

Calonne, N., Flin, F., Morin, S., Lesaffre, B., du Roscoat, S. R., and Geindreau, C.: Numerical and experimental investigations of the effective thermal conductivity of snow, Geophys. Res. Lett., 38, L23501, doi:10.1029/2011GL049234, 2011.

Calonne, N., Geindreau, C., Flin, F., Morin, S., Lesaffre, B., Rolland du Roscoat, S., and Charrier, P.: 3-D image-based numerical computations of snow permeability: links to specific surface area, density, and microstructural anisotropy, The Cryosphere, 6, 939-951, doi:10.5194/tc-6-939-2012, 2012.

Candille, G. and Talagrand, O.: Evaluation of probabilistic prediction systems for a scalar variable, Q. J. Roy. Meteorol. Soc., 131, 2131-2150, doi:10.1256/qj.04.71, 2005.
Carmagnola, C. M., Morin, S., Lafaysse, M., Domine, F., Lesaffre, B., Lejeune, Y., Picard, G., and Arnaud, L.: Implementation and evaluation of prognostic representations of the optical diameter of snow in the SURFEX/ISBA-Crocus detailed snowpack model, The Cryosphere, 8, 417-437, doi:10.5194/tc-8-417-2014, 2014.

Charrois, L., Cosme, E., Dumont, M., Lafaysse, M., Morin, S., Libois, Q., and Picard, G.: On the assimilation of optical reflectances and snow depth observations into a detailed snowpack model, The Cryosphere, 10, 1021-1038, doi:10.5194/tc-101021-2016, 2016.

Charron, M., Pellerin, G., Spacek, L., Houtekamer, P. L., Gagnon, N., Mitchell, H. L., and Michelin, L.: Toward Random Sampling of Model Error in the Canadian Ensemble Prediction System, Mon. Weather Rev., 138, 1877-1901, doi:10.1175/2009MWR3187.1, 2010.

Coléou, C. and Lesaffre, B.: Irreducible water saturation in snow: experimental results in a cold laboratory, Ann. Glaciol., 26, 6468, 1998.

Conger, S. M. and McClung, D. M.: Comparison of density cutters for snow profile observations, J. Glaciol, 55, 163-169, 2009.

D’Amboise, C. J. L., Müller, K., Oxarango, L., Morin, S., and Schuler, T. V.: Implementation of a physically based water percolation routine in the Crocus (V7) snowpack model, Geosci. Model Dev. Discuss., doi:10.5194/gmd-2017-56, in review, 2017.

Decharme, B., Boone, A., Delire, C., and Noilhan, J.: Local evaluation of the Interaction between Soil Biosphere Atmosphere soil multilayer diffusion scheme using four pedotransfer functions, J. Geophys. Res., 116, D20126, doi:10.1029/2011JD016002, 2011.

Decharme, B., Martin, E., and Faroux, S.: Reconciling soil thermal and hydrological lower boundary conditions in land surface models, J. Geophys. Res., 118, 7819-7834, doi:10.1002/jgrd.50631, 2013.

Decharme, B., Brun, E., Boone, A., Delire, C., Le Moigne, P., and Morin, S.: Impacts of snow and organic soils parameterization on northern Eurasian soil temperature profiles simulated by the ISBA land surface model, The Cryosphere, 10, 853-877, doi:10.5194/tc-10-853-2016, 2016.

Descamps, L., Labadie, C., Joly, A., Bazile, E., Arbogast, P., and Cébron, P.: PEARP, the Météo-France short-range ensemble prediction system, Q. J. Roy. Meteorol. Soc., 141, 1671-1685, doi:10.1002/qj.2469, 2014.

Doherty, S. J., Grenfell, T. C., Forsstrom, S., Hegg, D. L., Brandt, R. E., and Warren, S. G.: Observed vertical redistribution of black carbon and other insoluble light-absorbing particles in melting snow, J. Geophys. Res.-Atmos., 118, 5553-5569, doi:10.1002/jgrd.50235, 2013.

Domine, F., Morin, S., Brun, E., Lafaysse, M., and Carmagnola, C. M.: Seasonal evolution of snow permeability under equi-temperature and temperature-gradient conditions, The Cryosphere, 7, 1915-1929, doi:10.5194/tc-7-1915-2013, 2013.

Dumont, M., Arnaud, L., Picard, G., Libois, Q., Lejeune, Y., Nabat, P., Voisin, D., and Morin, S.: In situ continuous visible and nearinfrared spectroscopy of an alpine snowpack, The Cryosphere Discuss., doi:10.5194/tc-2016-266, in review, 2016.

Dupont, C., Chiriac, R., Gauthier, G., and Toche, F.: Heat capacity measurements of various biomass types and pyrolysis residues, FUEL, 115, 644-651, doi:10.1016/j.fuel.2013.07.086, 2014. 
Durand, Y., Brun, E., Mérindol, L., Guyomarc'h, G., Lesaffre, B., and Martin, E.: A meteorological estimation of relevant parameters for snow models, Ann. Glaciol., 18, 65-71, 1993.

Durand, Y., Giraud, G., Brun, E., Mérindol, L., and Martin, E.: A computer-based system simulating snowpack structures as a tool for regional avalanche forecasting, J. Glaciol., 45, 469-484, 1999.

Durand, Y., Guyomarc'h, G., and Mérindol, L.: Numerical experiments of wind transport over a mountainous instrumented site I: Regional scale, Ann. Glaciol., 32, 187-194, 2001.

Durand, Y., Giraud, G., Laternser, M., Etchevers, P., Mérindol, L., and Lesaffre, B.: Reanalysis of $44 \mathrm{Yr}$ of Climate in the French Alps (1958-2002): Methodology, Model Validation, Climatology, and Trends for Air Temperature and Precipitation, J. Appl. Meteor. Climat., 48, 429-449, doi:10.1175/2008JAMC1808.1, 2009.

Efron, B.: 1977 Rietz Lecture - Bootstrap methods, another look at the Jackknife, Ann. Stat., 7, 1-26, doi:10.1214/aos/1176344552, 1979.

Essery, R.: A factorial snowpack model (FSM 1.0), Geosci. Model Dev., 8, 3867-3876, doi:10.5194/gmd-8-3867-2015, 2015.

Essery, R., Morin, S., Lejeune, Y., and Bauduin-Ménard, C.: A comparison of 1701 snow models using observations from an alpine site, Adv. Water Res., 55, 131-148, doi:10.1016/j.advwatres.2012.07.013, 2013.

Essery, R., Kontu, A., Lemmetyinen, J., Dumont, M., and Ménard, C. B.: A 7-year dataset for driving and evaluating snow models at an Arctic site (Sodankylä, Finland), Geosci. Instrum. Method. Data Syst., 5, 219-227, doi:10.5194/gi-5-219-2016, 2016.

Flanner, M. G. and Zender, C. S.: Linking snowpack microphysics and albedo evolution, J. Geophys. Res., 111, D12208, doi:10.1029/2005JD006834, 2006.

Fortin, V., Abaza, M., Anctil, F., and Turcotte, R.: Why should ensemble spread match the RMSE of the ensemble mean?, J. Hydrometeor., 15, 1708-1713, doi:10.1175/JHM-D-14-0008.1, 2014.

Gallet, J.-C., Domine, F., Zender, C. S., and Picard, G.: Measurement of the specific surface area of snow using infrared reflectance in an integrating sphere at 1310 and $1550 \mathrm{~nm}$, The Cryosphere, 3, 167-182, doi:10.5194/tc-3-167-2009, 2009.

Gascon, G., Sharp, M., Burgess, D., Bezeau, P., Bush, A. B., Morin, S., and Lafaysse, M.: How well is firn densification represented by a physically-based multilayer model? Model evaluation for the Devon Ice Cap, Nunavut, Canada, J. Glaciol., 60, 694-704, doi:10.3189/2014JoG13J209, 2014.

Giraud, G.: MEPRA: an expert system for avalanche risk forecasting, in: Proceedings of the International snow science workshop, Breckenridge, Colorado, USA, 4-8 October 1992, 97-106, 1992.

Gneiting, T., Stanberry, L. I., Grimit, E. P., Held, L., and Johnson, N. A.: Assessing probabilistic forecasts of multivariate quantities, with an application to ensemble predictions of surface winds, Test, 17, 211-235, doi:10.1007/s11749-008-0114-x, 2008.

Gottardi, F., Paquet, E., Carrier, P., Laval, M.-T., Gailhard, J., and Garçon, R.: A decade of snow water equivalent monitoring in the French Mountain ranges, International Snow Science Workshop Grenoble/Chamonix/Mont-Blanc, Grenoble, France, 7-11 October, 926-930, 2013.
Habets, F., Boone, A., and Noilhan, J.: Simulation of a Scandinavian basin using the diffusion transfer version of ISBA, Global Planet. Change, 38, 137-149, doi:10.1016/S0921-8181(03)00016-X, 2003.

Hamill, T.: Interpretation of rank histograms for verifying ensemble forecasts, Mon. Weather Rev., 129, 550-560, doi:10.1175/15200493(2001)129<0550:IORHFV>2.0.CO;2, 2001.

IPCC: Climate Change 2013: The Physical Science Basis, in: Contribution of Working Group I to the Fifth Assessment Report of the Intergovernmental Panel on Climate Change, edited by: Stocker, T. F., Qin, D., Plattner, G.-K., Tignor, M., Allen, S. K., Boschung, J., Nauels, A., Xia, Y., Bex, V., and Midgley, P. M., Cambridge University Press, Cambridge, UK, New York, NY, USA, 1535 pp., 2013.

Jordan, R. E., Hardy, J. P., Perron, F. E., and Fisk, D. J.: Air permeability and capillary rise as measures of the pore structure of snow: an experimental and theoretical study, Hydrol. Proc., 13, 1733-1753, doi:10.1002/(SICI)10991085(199909)13:12/13<1733::AID-HYP863>3.0.CO;2-2, 1999.

Kochendorfer, J., Rasmussen, R., Wolff, M., Baker, B., Hall, M. E., Meyers, T., Landolt, S., Jachcik, A., Isaksen, K., Brækkan, R., and Leeper, R.: The quantification and correction of windinduced precipitation measurement errors, Hydrol. Earth Syst. Sci., 21, 1973-1989, doi:10.5194/hess-21-1973-2017, 2017.

Lafaysse, M., Morin, S., Coléou, C., Vernay, M., Serça, D., Besson, F., Willemet, J.-M., Giraud, G., and Durand, Y.: Toward a new chain of models for avalanche hazard forecasting in French mountain ranges, including low altitude mountains, in: Proceedings of the International Snow Science Workshop - Grenoble and Chamonix, 162-166, 2013.

Lehning, M., Bartelt, P., Brown, B., Russi, T., Stöckli, U., and Zimmerli, M.: SNOWPACK model calculations for avalanche warning based upon a new network of weather and snow stations, Cold Reg. Sci. Technol., 30, 145-157, 1999.

Lehning, M., Bartelt, P., Brown, B., Fierz, C., and Satyawali, P.: A physical SNOWPACK model for the Swiss avalanche warning, Part II: snow microstructure, Cold Reg. Sci. Technol., 35, 147167, doi:10.1016/S0165-232X(02)00073-3, 2002.

Libois, Q.: Evolution des propriétés physiques de la neige de surface sur le Plateau Antarctique, Observations et modélisation du transfert radiatif et du métamorphisme, $\mathrm{PhD}$ thesis, Université de Grenoble, 2014.

Libois, Q., Picard, G., Arnaud, L., Dumont, M., Lafaysse, M., Morin, S., and Lefebvre, E.: Summertime evolution of snow specific surface area close to the surface on the Antarctic Plateau, The Cryosphere, 9, 2383-2398, doi:10.5194/tc-9-2383-2015, 2015.

Louis, J.: A parametric model of vertical eddy fluxes in the atmosphere, Bound.-Lay. Meteorol., 17, 187-202, 1979.

Magnusson, J., Wever, N., Essery, R., Helbig, N., Winstral, A., and Jonas, T.: Evaluating snow models with varying process representations for hydrological applications, Water Resour. Res., 51, 2707-2723, doi:10.1002/2014WR016498, 2015.

Martin, E. and Lejeune, Y.: Turbulent fluxes above the snow surface, Ann. Glaciol., 26, 179-183, 1998.

Masson, V., Le Moigne, P., Martin, E., Faroux, S., Alias, A., Alkama, R., Belamari, S., Barbu, A., Boone, A., Bouyssel, F., Brousseau, P., Brun, E., Calvet, J.-C., Carrer, D., Decharme, B., Delire, C., Donier, S., Essaouini, K., Gibelin, A.-L., Giordani, H., 
Habets, F., Jidane, M., Kerdraon, G., Kourzeneva, E., Lafaysse, M., Lafont, S., Lebeaupin Brossier, C., Lemonsu, A., Mahfouf, J.-F., Marguinaud, P., Mokhtari, M., Morin, S., Pigeon, G., Salgado, R., Seity, Y., Taillefer, F., Tanguy, G., Tulet, P., Vincendon, B., Vionnet, V., and Voldoire, A.: The SURFEXv7.2 land and ocean surface platform for coupled or offline simulation of earth surface variables and fluxes, Geosci. Model Dev., 6, 929-960, doi:10.5194/gmd-6-929-2013, 2013.

Morin, S., Lejeune, Y., Lesaffre, B., Panel, J.-M., Poncet, D., David, P., and Sudul, M.: An 18-yr long (1993-2011) snow and meteorological dataset from a mid-altitude mountain site (Col de Porte, France, $1325 \mathrm{~m}$ alt.) for driving and evaluating snowpack models, Earth Syst. Sci. Data, 4, 13-21, doi:10.5194/essd-4-13-2012, 2012.

Navarre, J.: Modèle unidimensionnel d'évolution de la neige déposée: modèle perce-neige, La Météorologie, VI, 109-120, 1975.

Noilhan, J. and Mahfouf, J.-F.: The ISBA land surface parameterization scheme, Global Planet. Change, 17, 145-159, 1996.

Pahaut, E.: La métamorphose des cristaux de neige (Snow crystal metamorphosis), Monographies de la Météorologie Nationale, Vol. 96, Météo France, 1975.

Palmer, T., Buizza, R., Doblas-Reyes, F., Jung, T., Leutbecher, M., Shutts, G. J., Steinheimer, M., and Weisheimer, A.: Stochastic Parametrization and Model Uncertainty, Technical Memorandum 598, ECMWF, http://www.ecmwf.int/sites/default/files/elibrary/2009/ 11577-stochastic-parametrization-and-model-uncertainty.pdf, 2009.

Proksch, M., Rutter, N., Fierz, C., and Schneebeli, M.: Intercomparison of snow density measurements: bias, precision, and vertical resolution, The Cryosphere, 10, 371-384, doi:10.5194/tc10-371-2016, 2016.

Raleigh, M. S., Lundquist, J. D., and Clark, M. P.: Exploring the impact of forcing error characteristics on physically based snow simulations within a global sensitivity analysis framework, Hydrol. Earth Syst. Sci., 19, 3153-3179, doi:10.5194/hess-19-31532015, 2015.

Ritter, B. and Geleyn, J.-F.: A comprehensive radiation scheme for numerical weather prediction models with potential applications in climate simulations, Mon. Weather Rev., 120, 303-325, 1992.

Sauter, T. and Obleitner, F.: Assessing the uncertainty of glacier mass-balance simulations in the European Arctic based on variance decomposition, Geosci. Model Dev., 8, 3911-3928, doi:10.5194/gmd-8-3911-2015, 2015.

Scheuerer, M. and Hamill, T. M.: Variogram-Based Proper Scoring Rules for Probabilistic Forecasts of Multivariate Quantities, Mon. Weather Rev., 143, 1321-1334, doi:10.1175/MWR-D-1400269.1, 2015.

Schleef, S., Löwe, H., and Schneebeli, M.: Influence of stress, temperature and crystal morphology on isothermal densification and specific surface area decrease of new snow, The Cryosphere, 8, 1825-1838, doi:10.5194/tc-8-1825-2014, 2014.

Schmucki, E., Marty, C., Fierz, C., and Lehning, M.: Evaluation of modelled snowdepth and snow water equivalent at three contrasting sites in Switzerland using SNOWPACK simulations driven by different meteorological data input, Cold Reg. Sci. Technol., 99, 27-37, 2014.

Smith, C. D., Kontu, A., Laffin, R., and Pomeroy, J. W.: An assessment of two automated snow water equivalent instruments during the WMO Solid Precipitation Intercomparison Experiment, The Cryosphere, 11, 101-116, doi:10.5194/tc-11-101-2017, 2017.

Sterle, K. M., McConnell, J. R., Dozier, J., Edwards, R., and Flanner, M. G.: Retention and radiative forcing of black carbon in eastern Sierra Nevada snow, The Cryosphere, 7, 365-374, doi:10.5194/tc-7-365-2013, 2013.

Sun, S., Jin, J., and Xue, Y.: A simple snow-atmosphere-soil transfer (SAST) model, J. Geophys. Res., 55, 1206-1216, doi:10.1007/s11430-011-4328-5, 1999.

Swinbank, R., Kyouda, M., Buchanan, P., Froude, L., Hamill, T. M., Hewson, T. D., Keller, J. H., Matsueda, M., Methven, J., Pappenberger, F., Scheuerer, M., Titley, H. A., Wilson, L., and Yamaguchi, M.: The TIGGE project and its achievements, B. Am. Meteorol. Soc., 97, 49-67, doi:10.1175/BAMS-D-13-00191.1, 2016.

Teufelsbauer, H.: A two-dimensional snow creep model for alpine terrain, Nat. Hazards, 56, 481-497, doi:10.1007/s11069-0109515-8, 2011.

Thiboult, A., Anctil, F., and Boucher, M.-A.: Accounting for three sources of uncertainty in ensemble hydrological forecasting, Hydrol. Earth Syst. Sci., 20, 1809-1825, doi:10.5194/hess-20-18092016, 2016.

Thorarinsdottir, T. L., Scheuerer, M., and Heinz, C.: Assessing the Calibration of High-Dimensional Ensemble Forecasts Using Rank Histograms, J. Comp. Graph. Stat., 25, 105-122, doi:10.1080/10618600.2014.977447, 2016.

Vernay, M., Lafaysse, M., Merindol, L., Giraud, G., and Morin, S.: Ensemble Forecasting of snowpack conditions and avalanche hazard, Cold. Reg. Sci. Technol., 120, 251-262, doi:10.1016/j.coldregions.2015.04.010, 2015.

Vikhamar-Schuler, D., Müller, K., and Engen-Skaugen, T.: Snow modeling using SURFEX with the CROCUS snow scheme, Report 07/2011, met.no, http://met.no/Forskning/Publikasjoner/ ?module=Files; action=File.getFile;ID=4367, 2011.

Vionnet, V., Brun, E., Morin, S., Boone, A., Faroux, S., Le Moigne, P., Martin, E., and Willemet, J.-M.: The detailed snowpack scheme Crocus and its implementation in SURFEX v7.2, Geosci. Model Dev., 5, 773-791, doi:10.5194/gmd-5-773-2012, 2012.

Vionnet, V., Dombrowski-Etchevers, I., Lafaysse, M., Quéno, L., Seity, Y., and Bazile, E.: Numerical weather forecasts at kilometer scale in the French Alps: evaluation and applications for snowpack modelling, J. Hydrometeor., 17, 2591-2614, doi:10.1175/JHM-D-15-0241.1, 2016.

Warren, S.: Optical properties of snow, Rev. Geophys., 20, 67-89, doi:10.1029/RG020i001p00067, 1982.

Wever, N., Fierz, C., Mitterer, C., Hirashima, H., and Lehning, M.: Solving Richards Equation for snow improves snowpack meltwater runoff estimations in detailed multi-layer snowpack model, The Cryosphere, 8, 257-274, doi:10.5194/tc-8-257-2014, 2014.

Wever, N., Schmid, L., Heilig, A., Eisen, O., Fierz, C., and Lehning, M.: Verification of the multi-layer SNOWPACK model with different water transport schemes, The Cryosphere, 9, 2271-2293, doi:10.5194/tc-9-2271-2015, 2015.

WSL: Meteorological and snowpack measurements from Weissfluhjoch, Davos, Switzerland., Tech. rep., WSL Institute for Snow and Avalanche Research SLF, doi:10.16904/1, 2015.

Yen, Y.-C.: Review of the thermal properties of snow, ice and sea ice, Tech. Rep. 81-10, Cold Regions Research and Engineering Laboratory, Hanover, NH, 1981. 